\title{
Efeito da aplicação de biofertilizante líquido no desenvolvimento do sorgo irrigado com água salobra
}

\section{Effect of biofertilizer application on sorghum plants irrigated with saline water}

\author{
Robson Alexsandro de SOUSA ${ }^{1}$; Claudivan Feitosa de LACERDA ${ }^{2}$; Emerson Moreira de AGUIAR ${ }^{3}$; \\ Sidney Carlos PRAXEDES ${ }^{4}$
}

${ }^{1}$ Autor para correspondência Prof Doutor, Universidade Federal do Rio Grande do Norte, Unidade Acadêmica Especializada em Ciências Agrárias, Caixa Postal 07, Macaíba, RN, 59092-160, email: rasousaufrn@gmail.com

${ }^{2}$ Prof Doutor, Universidade Federal do Ceará, e-mail: claudivan_@hotmail.com

${ }^{3}$ Prof Doutor, Universidade Federal do Rio Grande do Norte, e-mail: emersonmaufrn@gmail.com

${ }^{4}$ Prof Doutor, Universidade Federal do Rio Grande do Norte, e-mail: scpraxedes@eaj.ufrn.br

Recebido em: 16-01-2018; Aceito em: 11-07-2018

\section{Resumo}

Com o objetivo de avaliar os efeitos da salinidade da água de irrigação e doses de biofertilizante, sobre o desenvolvimento de plantas de sorgo [Sorghum bicolor (L.) Moench.] cv. BRS Ponta Negra, desenvolveu-se este trabalho em casa de vegetação. As plantas foram cultivadas em vasos contendo $23 \mathrm{~kg}$ de solo arenoso. Foram testados quatro níveis de salinidade: 0,2; 2,0; 4,0 e 6,0 dS m-1. Para a obtenção dos níveis de salinidade, utilizouse da água de açude adicionada com sais de $\mathrm{NaCl}, \mathrm{CaCl}_{2} 2 \mathrm{H}_{2} \mathrm{O}$ e $\mathrm{MgCl}_{2} 6 \mathrm{H}_{2} \mathrm{O}$, na proporção de 7:2:1. As doses de biofertilizante foram 75; 150; 225 e $300 \mathrm{~L} \mathrm{ha}^{-1}$. O delineamento experimental foi o inteiramente casualizado, com quatro repetições, em esquema fatorial $4 \times 4$. Foram avaliadas as seguintes variáveis: massa seca total; diâmetro do colmo; altura das plantas; área foliar total; suculência foliar; massa específica foliar; teores de sódio, potássio, cloro, cálcio, magnésio e fósforo, nos colmos + bainhas e limbos foliares; teores de prolina e carboidratos nas folhas. Todas as variáveis analisadas foram afetadas negativamente pelo aumento da salinidade da água de irrigação. $O$ aumento da concentração de biofertilizante, nos limites empregados no presente estudo, não minorou os efeitos da salinidade no crescimento de plantas de sorgo.

Palavras-chave adicionais: crescimento; irrigação; salinidade; Sorghum bicolor L.

\begin{abstract}
The objective of this study was to evaluate the effects of irrigation water salinity and doses biofertilizer on the development in sorghum [Sorghum bicolor (L.) Moench.] cv. BRS Ponta Negra, in greenhouse. The plants were grown in pots containing $23 \mathrm{~kg}$ of sandy soil. Four salinity levels were tested: $0.2 ; 2.0 ; 4.0$; and $6.0 \mathrm{dS} \mathrm{m}^{-1}$, adding to fresh water the salts of $\mathrm{NaCl}, \mathrm{CaCl}_{2} 2 \mathrm{H}_{2} \mathrm{O}$ and $\mathrm{MgCl}_{2} 6 \mathrm{H}_{2} \mathrm{O}$ in a 7:2:1 ratio. Biofertilizer doses were 75, 150, 225 and $300 \mathrm{~L} \mathrm{ha}^{-1}$. The experimental design was completely randomized with four replications in a factorial $4 \times 4$. The following variables were assessed: total dry matter; stem diameter; plant height; total leaf area; leaf succulence; leaf density; sodium, potassium, chloride, calcium, magnesium and phosphorus in the leaves and culms + sheath of plants; proline and carbohydrates were measured only in the leaves. All the analyzed variables were negatively affected by the increase in water salinity. Increasing the concentration of biofertilizer within the limits used in the present study, did not diminish the effects of salinity on growth of sorghum plants.
\end{abstract}

Additional keywords: growth; irrigation; salinity; Sorghum bicolor L.

\section{Introdução}

A região Nordeste brasileira, principalmente em sua porção de semiárido, apresenta-se com escassez de água, na qual a razão entre disponibilidade e a demanda pelos recursos hídricos é uma das mais preocupantes do País (Dias et al., 2012). Gradativamente, a água disponível para consumo humano e para a prática agrícola vem sendo reduzida tanto em qualidade como em quantidade, sendo necessário o uso alternativo de água de qualidade inferior para atender à demanda da irrigação na região do semiárido Nordestino (Silva et al., 2014), cujo elevado déficit hídrico contribui também para o incremento da salinidade da água e do solo nas áreas irrigadas (Montenegro et al., 2013).

O aumento das áreas comprometidas por sais nos perímetros irrigados do Nordeste brasileiro gera transtornos econômicos e sociais à região semiárida onde o sistema produtivo depende da irrigação, além de limitar novas áreas de produção a serem instaladas para atender à crescente demanda alimentar (Medeiros et al., 2010). Em ambiente salino, o crescimento das plantas é afetado pela interação complexa de hormônios, efeitos osmóticos, efeito de íons específicos e desequilíbrios nutricionais, provavelmente, 
tudo podendo ocorrer simultaneamente (Ahamd et al., 2014; Badar et al., 2015).

Várias alternativas para minorar os efeitos da água salina, tanto no solo quanto nas plantas, vêm sendo testadas (Lacerda et al., 2010), dentre elas a aplicação de biofertilizantes (Sahoo et al., 2014; Oliveira et al., 2015) aparece como forma de reativar a atividade microbiológica do solo, prejudicada pelo conteúdo elevado de sais da água de irrigação (Van Horn et al., 2014). Os efeitos benéficos que os microrganismos produzem sobre o solo e as plantas não são somente sobre a disponibilidade de nutrientes, mas também no crescimento, na fixação de nitrogênio, na diminuição do estresse hídrico, entre outros (Miransari, 2013).

A aplicação de biofertilizantes desempenha um papel vital na manutenção da fertilidade do solo a longo prazo (Mishra et al., 2013), mantendo o ambiente do solo rico em todos os tipos de micro e macronutrientes via fixação biológica de nitrogênio, fosfato e potássio, solubilização ou mineralização, com liberação de substâncias que regulam o crescimento das plantas e a biodegradação da matéria orgânica no solo, sendo utilizado em condições de estresse salino como forma de atenuar os efeitos deletérios da salinidade (Badar et al., 2015). De acordo com Lacerda et al. (2010), a importância do uso de biofertilizantes líquidos, na forma de fermentados microbianos simples ou enriquecidos, está nos quantitativos dos elementos, na diversidade dos nutrientes minerais quelatizados e disponibilizados pela atividade biológica e como ativador enzimático do metabolismo vegetal.

O sorgo é considerado tolerante à salinidade (Saadat \& Homaee, 2015), apresentando-se como alternativa de substituição do milho na alimentação animal (Moreira et al., 2014), em função do bom teor de proteína, amido e outros nutrientes (Wong et al, 2010); além disso, trata-se de uma importante fonte de produção de forragem nas regiões semiáridas (Ngara et al., 2012), especialmente no semiárido Nordestino, devido à sua adaptabilidade a baixos índices pluviométricos e a altas temperaturas (Avelino et al., 2011). Entretanto, são escassas na literatura pesquisas com a aplicação de doses de biofertilizante no sorgo no intuito de mitigar os efeitos deletérios da salinidade.

Portanto, este trabalho objetivou avaliar o crescimento e os teores de solutos orgânicos e inorgânicos nas plantas de sorgo da cultivar BRS Ponta Negra submetidas a diferentes doses de biofertilizantes e irrigadas com águas de crescentes níveis de salinidade.

\section{Material e métodos}

O experimento foi realizado em casa de vegetação localizada na Escola Agrícola de Jundiaí Unidade Acadêmica Especializada em Ciências Agrá- rias, pertencente à Universidade Federal do Rio Grande do Norte, localizada no município de Macaíba - RN, nas coordenadas geográficas de 553'02"S $35^{\circ} 21^{\prime} 49^{\prime \prime} \mathrm{W}$ e a uma altitude de $17 \mathrm{~m}$. O clima da região, de acordo com a classificação de Köppen, é do tipo As, tropical com estação seca, com precipitação pluvial média anual de $1.134 \mathrm{~mm}$, temperatura média anual em torno de $25,9 \stackrel{\circ}{\mathrm{C}}$ e umidade relativa do ar de $76 \%$ (Vianello \& Alves, 1991).

Utilizou-se da cultura do sorgo cv. BRS Ponta Negra, desenvolvida pela Embrapa Milho e Sorgo, em conjunto com a Empresa de Pesquisa Agropecuária do Rio Grande do Norte - EMPARN. Essa cultivar é classificada na categoria forrageiro de pequeno porte, apresentando um ciclo médio de 90 dias entre o plantio e o ponto de colheita, com dupla aptidão, produtividade média de grãos entre 3 a 5 t ha $^{-1}$ (sequeiro) e de 6 a 8 t ha $^{-1}$ (irrigado), um rendimento de massa verde de 40 a $60 \mathrm{t} \mathrm{ha}^{-1}$ (por corte) e de massa seca de 14 a $15 \mathrm{t} \mathrm{ha}^{-1}$ (por corte), e florescimento entre 60 e 75 dias (Santos et al., 2007).

Foram avaliadas quatro doses de biofertilizante comercial (75; 150; 225 e $300 \mathrm{~L} \mathrm{ha}^{-1}$ ), e as plantas de sorgo cv. BRS Ponta Negra foram irrigadas com quatro níveis de salinidade da água $(0,2 ; 2,0 ; 4,0$ e $6,0 \mathrm{dS} \mathrm{m}^{-1}$ ). O delineamento experimental utilizado foi o inteiramente casualizado, com quatro repetições, no esquema fatorial $4 \times 4$, totalizando 16 tratamentos.

Para o preparo das soluções salinas, foram utilizados os sais de $\mathrm{NaCl}, \mathrm{CaCl}_{2} \cdot 2 \mathrm{H}_{2} \mathrm{O}$ e $\mathrm{MgCl}_{2} \cdot 6 \mathrm{H}_{2} \mathrm{O}$ dissolvidos em água de açude, na proporção de 7:2:1, obedecendo-se à relação entre a condutividade elétrica da água de irrigação (CEa) e sua concentração ( $\mathrm{mmol}_{\mathrm{C}} \mathrm{L}^{-1}=\mathrm{CE} \times 10$ ), extraída de Rhoades et al. (1992). Na Tabela 1, observa-se a composição química das águas utilizadas para a irrigação no experimento.

A quantidade de água aplicada foi estimada com base no princípio do lisímetro de drenagem, mantendo o solo na capacidade de campo e uma fração de lixiviação de 0,15 para evitar o acúmulo excessivo de sais no solo (Ayers \& Westcot, 1999). A irrigação foi diária, e o volume aplicado foi calculado pela diferença entre a água aplicada e a água drenada na irrigação anterior, dividindo-se por 0,85. Até o desbaste, utilizou-se para a irrigação a água de açude do Bebo (S0), localizado na Escola Agrícola de Jundiaí, Macaíba - RN, cuja análise química se encontra na Tabela 1.

Utilizou-se como fonte de matéria orgânica, de biofertilizante comercial, na forma líquida, composto de água, quelato de cálcio, ácidos carboxílicos, nitrato de cálcio, nitrato de magnésio e ácido acético, conforme informações oriundas do fabricante, cujas características químicas estão representadas na Tabela 2. 
Tabela 1 - Composição química das águas de irrigação usadas no experimento. Chemical composition of the irrigation water used in the research.

\begin{tabular}{|c|c|c|c|c|c|c|c|c|c|c|}
\hline Água & $\mathrm{Ca}^{2+}$ & $\mathrm{Mg}^{2+}$ & $\begin{array}{c}\mathrm{Na}^{+} \\
---(\mathrm{mr}\end{array}$ & $\mathrm{K}^{+}$ & $\mathrm{Cl}^{-}$ & $\mathrm{CO}_{3}^{-}$ & $\mathrm{HCO}_{3}^{-}$ & RAS & $\mathrm{pH}$ & $\begin{array}{c}\mathrm{CE}_{\mathrm{a}} \\
\left(\mathrm{dS} \mathrm{m}^{-1}\right)\end{array}$ \\
\hline S0 & 0,15 & 0,22 & 0,85 & 0,20 & 1,12 & 0,00 & 0,42 & 1,11 & 7,0 & 0,20 \\
\hline S1 & 3,71 & 1,32 & 10,37 & 0,15 & 16,35 & 0,00 & 0,40 & 4,48 & 6,7 & 2,00 \\
\hline S2 & 7,63 & 2,75 & 26,97 & 0,14 & 40,65 & 0,00 & 0,44 & 9,22 & 6,7 & 4,00 \\
\hline S3 & 12,43 & 5,49 & 38,55 & 0,21 & 60,73 & 0,00 & 0,46 & 10,90 & 6,6 & 6,00 \\
\hline
\end{tabular}

Fonte: Laboratório de Análises de Solo, Água e Planta - EMPARN. $\mathrm{CE}_{\mathrm{a}}=$ condutividade elétrica da água de irrigação; RAS = relação de adsorção de sódio; $S 0$ = água de açude do Bebo; $S 1$ = solução salina 1 ; $S 2$ = solução salina 2 ; S3 = solução salina 3 .

Tabela 2 - Composição química do biofertilizante líquido concentrado utilizado no experimento. Chemical composition of the concentrated liquid biofertilizer used in the research.

\begin{tabular}{cccccccccc}
\hline $\mathrm{Ca}^{2+}$ & $\mathrm{Mg}^{2+}$ & $\mathrm{Na}^{+}$ & $\begin{array}{c}\mathrm{K}^{+} \\
-\end{array} \mathrm{Cl}^{-}$ & $\mathrm{CO}_{3}^{2-}$ & $\mathrm{HCO}_{3}{ }^{-}$ & $\mathrm{RAS}_{\mathrm{B}}$ & $\mathrm{pH}$ & $\mathrm{CE}_{\mathrm{B}}$ \\
\hline 246,6 & 80,4 & 70,11 & 10,3 & 900,00 & 0,00 & 0,00 & 5,5 & 2,8 & 704 \\
\hline
\end{tabular}

Fonte: Laboratório de Fertilidade do Solo e Nutrição de Plantas - DCS/UFERSA. CE $E_{\mathrm{B}}=$ condutividade elétrica do biofertilizante concentrado; $\mathrm{RAS}_{\mathrm{B}}=$ relação de adsorção de sódio do biofertilizante.

Para a instalação do experimento, colocaram-se aproximadamente $23 \mathrm{~kg}$ de solo arenoso (Tabela 3) em vasos plásticos de $32 \mathrm{~cm}$ de diâmetro na base maior, $24 \mathrm{~cm}$ de diâmetro na base menor e altura de $34 \mathrm{~cm}$, perfurados na face inferior. Antes, porém, foi colocada uma camada de brita de $2 \mathrm{~cm}$, para facilitar a drenagem. Logo em seguida, os vasos foram colocados em uma das bancadas da casa de vegetação, onde se procedeu à lavagem com $2 \mathrm{~L}$ de água de açude, por três vezes, no intuito de retirar a argila ainda existente neste solo. A semeadura foi realizada colocando-se dez sementes de sorgo em cada vaso.

Tabela 3 - Análises químicas e classificação textural do solo utilizado no experimento. Chemical analyzes and textural classification of the soil used in the research.

\begin{tabular}{cccccccccccccccc}
\hline $\mathrm{Ca}^{2+}$ & $\mathrm{Mg}^{2+}$ & $\mathrm{Na}^{+}$ & $\mathrm{K}^{+}$ & $\mathrm{H}^{+}+\mathrm{Al}^{3+}$ & $\mathrm{Al}^{3+}$ & $\mathrm{SB}$ & $\mathrm{t}$ & $\mathrm{P}$ & $\mathrm{CH}$ & $\begin{array}{c}\mathrm{C} E_{\mathrm{es}} \\
\mathrm{PST}\end{array}$ & $\mathrm{V}$ & $\mathrm{Dg}$ & $\mathrm{T}$ \\
\hline 0,8 & 0,7 & 0,05 & 0,13 & 1,82 & 0,65 & 1,7 & 3,5 & 1,31 & 5,0 & 0,1 & 1,0 & 49 & 1,46 & Areia \\
\hline
\end{tabular}

Fonte: Laboratório de Solos e Água - DCS/CCA/UFC. SB = soma de bases; $\mathrm{t}$ = capacidade de troca catiônica efetiva; $\mathrm{pH}=\mathrm{pH}$ em água (1:2,5); $\mathrm{CE}_{\mathrm{es}}=$ condutividade elétrica do extrato de saturação; PST = porcentagem de sódio trocável; $\mathrm{V}=$ saturação por bases; $\mathrm{Dg}=$ densidade global; $\mathrm{T}=$ textura .

O desbaste foi realizado dez dias após a semeadura, deixando-se duas plantas por vaso. Após o desbaste, iniciou-se a aplicação dos tratamentos com água de diferentes salinidades. A adubação química consistiu na aplicação de ureia $(0,94 \mathrm{~g}$ vaso-1 $)$, cloreto de potássio $\left(0,49 \mathrm{~g}\right.$ vaso $\left.^{-1}\right)$ e superfosfato simples $\left(1,96 \mathrm{~g} \mathrm{vaso}^{-1}\right)$, seguindo a recomendação para a cultura (Lima et al., 2010). Realizou-se o monitoramento diário do ensaio para evitar o ataque de pragas e a infestação de doenças.

As aplicações das doses de biofertilizante tiveram início aos dez dias após a semeadura. O biofertilizante foi diluído em água não salina, colocando-se em cada vaso as doses de 0,$75 ; 1,5 ; 2,25$ e 3,00 mL/vez, correspondentes às doses de biofertilizante de 75; 150; 225 e $300 \mathrm{~L} \mathrm{ha}^{-1}$, respectivamente, cujas análises químicas estão descritas na Tabela 4. Colocou-se em cada vaso a quantidade de $150 \mathrm{~mL}$ de biofertilizante diluído. As aplicações foram feitas no período da manhã, com intervalos de dois dias, totalizando, ao final do experimento, dezessete aplicações de biofertilizante diluído.

Aos sessenta dias após a semeadura, procedeu-se à coleta do experimento, sendo estimada a área foliar das plantas, utilizando-se da Equação 1, segundo a metodologia proposta por Hassan et al. (2010). Determinou-se, também, o peso fresco dos limbos foliares, os colmos + bainhas e o sistema radicular.

$\mathrm{AFT}=\mathrm{C} \times \mathrm{L} \times 0,75$

Em que: AFT é a área foliar total $\left(\mathrm{cm}^{2}\right)$; $\mathrm{C}$ é o maior comprimento do limbo foliar (cm), e $L$ é a maior largura da folha $(\mathrm{cm})$. 
Tabela 4 - Composição química do biofertilizante diluído utilizado no experimento. Chemical composition of the concentrated liquid biofertilizer used in the research.

\begin{tabular}{crrrrrrrrrr}
\hline $\begin{array}{c}\text { Biofertilizante } \\
\left(\mathrm{L} \mathrm{ha}^{-1}\right)\end{array}$ & $\mathrm{Ca}^{2+}$ & $\mathrm{Mg}^{2+}$ & $\mathrm{Na}^{+}$ & $\mathrm{K}^{+}$ & $\mathrm{Cl}^{-}$ & $\mathrm{CO}_{3}^{-}$ & $\mathrm{HCO}_{3}$ & $\mathrm{RAS}_{\text {bio }}$ & $\mathrm{pH}$ & $\begin{array}{c}\mathrm{CE}_{\text {bio }} \\
\left(\mathrm{dS} \mathrm{m}^{-1}\right)\end{array}$ \\
\hline 75 & 34,00 & 14,00 & 0,46 & 0,07 & 25,00 & 0,00 & 1,20 & 0,10 & 4,4 & 4,04 \\
150 & 63,00 & 24,30 & 0,58 & 0,11 & 25,00 & 0,00 & 1,70 & 0,10 & 4,3 & 7,26 \\
225 & 91,50 & 31,80 & 0,81 & 0,16 & 25,00 & 0,00 & 1,90 & 0,10 & 4,4 & 9,78 \\
300 & 114,80 & 46,70 & 1,10 & 0,21 & 30,00 & 0,00 & 2,00 & 0,10 & 4,4 & 12,51 \\
\hline
\end{tabular}

Fonte: Laboratório de Fertilidade do Solo e Nutrição de Plantas - DCS/UFERSA. CE $_{\text {bio }}=$ condutividade elétrica do biofertilizante diluído; RAS bio = relação de adsorção de sódio do biofertilizante diluído.

Durante a coleta do experimento, foram realizadas medições de altura da planta, utilizando-se de uma trena, medindo-se da superfície do solo até à inserção da folha mais nova; e diâmetro do colmo + bainhas, com um paquímetro digital Insize, a uma altura de $10 \mathrm{~cm}$ a partir da superfície do solo.

O material coletado (colmos + bainhas, limbos foliares e sistema radicular), após pesagem, foi acondicionado em sacos de papel e levados à estufa com circulação forçada de ar, a $65{ }^{\circ} \mathrm{C}$, por um período de sete dias, quando se constatou o peso constante das amostras, visando à obtenção da massa seca do material.

Determinou-se a massa específica foliar (g MS dm ${ }^{-2}$ ), utilizando-se da Equação 2, e a suculência foliar $\left(\mathrm{g} \mathrm{H}_{2} \mathrm{O} \mathrm{dm} \mathrm{dm}^{-2}\right) \mathrm{com}$ a Equação 3, conforme Mantovani (1999).

MEF $=$ MS/AFT

Em que: MEF é a massa específica foliar ( $\left.\mathrm{g} \mathrm{MS} \mathrm{dm}^{-2}\right)$; MS é a massa seca das folhas (g); AFT é a área foliar total $\left(\mathrm{dm}^{-2}\right)$.

SUC $=\frac{(M F-M S)}{A F T}$

Em que: SUC é a suculência foliar $\left(\mathrm{g} \mathrm{H}_{2} \mathrm{O} \mathrm{dm}{ }^{-2}\right)$; MF é a massa fresca das folhas (g); MS é a massa seca das folhas (g); AFT é a área foliar total $\left(\mathrm{dm}^{-2}\right)$.

A partir da massa seca dos colmos + bainhas e limbos foliares, que foram finamente triturados em moinho tipo Willey, preparou-se o extrato para a determinação dos teores de $\mathrm{Na}^{+}, \mathrm{Ca}^{2+}, \mathrm{K}^{+}, \mathrm{P}$ e $\mathrm{Mg}^{2+}$. $\mathrm{O}$ extrato foi preparado, utilizando $200 \mathrm{mg}$ do pó diluído em $15 \mathrm{~mL}$ de ácido clorídico $1 \mathrm{~N}$ e, em seguida, agitado por 60 minutos e filtrado, utilizando-se de papel-filtro de filtragem rápida (Miyazawa et al., 1984). Os teores de $\mathrm{Na}^{+}, \mathrm{Ca}^{2+}$, e K $\mathrm{K}^{+}$foram determinados por fotometria de chama, enquanto que os teores de $P$, por colorimetria, e os teores de $\mathrm{Mg}^{2+}$, por espectrofotometria de absorção atômica (Malavolta et al., 1989).

Os teores de $\mathrm{Cl}^{-}$foram determinados em extratos aquosos, feitos a partir da diluição de aproximadamente $100 \mathrm{mg}$ do material seco e moído, dos colmos + bainhas e dos limbos foliares, com $10 \mathrm{~mL}$ de água deionizada. $\mathrm{O}$ homogeneizado foi mantido em agitação durante, aproximadamente, 60 minutos; e, posteriormente, filtrado em papel-filtro. Para a determinação do $\mathrm{Cl}$-, utilizou-se da alíquota de $0,5 \mathrm{~mL}$ do extrato, completado para $3,0 \mathrm{~mL}$ com água deionizada. Em seguida, adicionou-se $0,5 \mathrm{~mL}$ de mistura de $\mathrm{Hg}(\mathrm{SCN})_{2}$ 13,2mM, em metanol, e de $\mathrm{Fe}\left(\mathrm{NO}_{3}\right)_{3} 20,2 \%$ $(4+1)$, lendo-se a absorbância a $460 \mathrm{~nm}$ após 15 minutos. Os teores de $\mathrm{Cl}^{-}$foram determinados por meio de uma curva de calibração, utilizando-se $\mathrm{NaCl}$ como padrão, preparada nas condições anteriores (Gaines et al., 1984). Cada repetição foi dosada por uma amostra simples, sem replicata.

Durante o procedimento de coleta do experimento, retiraram-se a segunda e a terceira folhas completamente expandidas a partir do ápice da planta, sendo pesadas e acondicionadas em papel-alumínio e, logo em seguida, colocadas em freezer para posteriormente, serem liofilizadas. Este material foi utilizado para as determinações de solutos orgânicos.

$\mathrm{O}$ extrato para a determinação dos solutos orgânicos foi obtido pela homogeneização de $100 \mathrm{mg}$ do pó resultante da liofilização das folhas de sorgo com 5,0 $\mathrm{mL}$ de água deionizada. $\mathrm{O}$ homogenato foi colocado em banho-maria a $90^{\circ} \mathrm{C}$, durante uma hora. $\mathrm{Em}$ seguida, as amostras foram centrifugadas a $5.000 \times \mathrm{g}$ por $15 \mathrm{~min}$ à temperatura ambiente $\left(25^{\circ} \mathrm{C}\right)$. Por último, filtrou-se o sobrenadante, o qual foi armazenado em freezer até o momento das análises. $O$ teor de carboidratos nos limbos foliares foi determinado utilizando-se de alíquotas de $100 \mu \mathrm{L}$ do extrato diluído em $400 \mu \mathrm{L}$ de água desmineralizada, colocados em tubos de ensaio; adicionaram-se $500 \mu \mathrm{L}$ de fenol a $5 \%$ e 2,5 mL de ácido sulfúrico concentrado, posteriormente agitados em vórtex. Deixou-se esfriar e procedeu-se à leitura por espectrofotômetro a $490 \mathrm{~nm}$. A concentração de carboidratos foi determinada através de curva de calibração, utilizando-se como padrão de glicose (Dubois et al., 1956).

Para a determinação da prolina nos limbos foliares, alíquotas de $1 \mathrm{~mL}$ do extrato foram colocadas em tubos de ensaio com tampa rosqueável, aos quais foram adicionados $1 \mathrm{~mL}$ de ninidrina ácida e $1 \mathrm{~mL}$ de ácido acético glacial. A mistura foi agitada em vórtex e 
colocada em banho-maria, a $90{ }^{\circ} \mathrm{C}$, por 60 minutos. Após esse período, resfriaram-se os tubos com um banho de gelo. Depois do resfriamento, adicionaramse a cada tubo $2 \mathrm{~mL}$ de Tolueno e agitaram-se em vórtex. A fração orgânica (superior) foi retirada com o auxílio de uma pipeta Pasteur, procedendo-se à leitura a $520 \mathrm{~nm}$, em um espectrofotômetro. A concentração de prolina foi determinada usando-se curva de calibração, utilizando-se de prolina pura como padrão (Bates et al., 1973).

Os resultados das variáveis foram submetidos à análise de variância, e as médias, comparadas pelo teste de Tukey, com $p<0,05$ (comparação das doses de biofertilizante), utilizando-se do programa ASSISTAT 7.7 Beta (Silva \& Azevedo, 2016). A análise de regressão foi empregada para a avaliação dos efeitos da salinidade da água de irrigação e da interação, quando significativa.

\section{Resultados e discussão}

\section{Crescimento vegetativo das plantas}

Todas as variáveis analisadas apresentaram significância estatísticas $(p<0,01)$ para o fator níveis de salinidade (Tabela 5 ), excetuando-se a variável massa específica foliar, que não apresentou significância estatística $(p>0,05)$. Verifica-se, ainda, que as variáveis altura de plantas (ALT), diâmetro do colmo (DIAM), área foliar total (AFT) e massa específica foliar (MEF) foram, estatisticamente, influenciadas $(p<0,01$ ou $p<0,05$ ) pela dose de biofertilizante, enquanto as demais variáveis não apresentaram significância estatística, $p>0,05$. A interação entre os fatores não influenciou nenhuma das variáveis analisadas.

Tabela 5 - Valores do quadrado médio e significância estatística para massa seca total (MST), altura de plantas (ALT), diâmetro do colmo (DIAM), área foliar total (AFT), massa específica foliar (MEF) e suculência foliar (SUC) em plantas de sorgo cv. BRS Ponta Negra, submetidas a diferentes doses de biofertilizante e irrigadas com água salobra. Mean square values and statistical significance for total dry massr (MST), plant height (ALT), stem diameter (DIAM), total leaf area (AFT), specific leaf mass (MEF) and leaf succulence (SUC) in sorghum cv. BRS Ponta Negra, submitted to different biofertilizer dosis and irrigated with saline water.

\begin{tabular}{lcccccc}
\hline \multirow{2}{*}{ Fontes de variação } & \multicolumn{5}{c}{ Quadrados médios } \\
& MST & ALT & DIAM & AFT & MEF & SUC \\
\hline SAL & $12.432,41^{\star \star}$ & $14.589,40^{\star *}$ & $8,73^{\star *}$ & $1.364 .828,96^{\star \star}$ & $0,006^{\text {ns }}$ & $0,754^{\star *}$ \\
BIOF & $195,77^{\text {ns }}$ & $3.041,40^{\star *}$ & $0,08^{*}$ & $403.007,47^{\star \star}$ & $0,028^{\star}$ & $0,077^{\text {ns }}$ \\
SAL $\times$ BIOF & $302,52^{\text {ns }}$ & $310,95^{\text {ns }}$ & $1,19^{\text {ns }}$ & $67.441,60^{\text {ns }}$ & $0,005^{\text {ns }}$ & $0,037^{\text {ns }}$ \\
RESÍDUO & 353,50 & 386,70 & 1,87 & $63.765,88$ & 0,008 & 0,052 \\
\hline CV $(\%)$ & 15,98 & 15,90 & 8,85 & 5,58 & 12,78 & 9,92 \\
\hline
\end{tabular}

${ }^{*}$ Significativo pelo teste $\mathrm{F}$ a $5 \%$; ${ }^{*}$ Significativo pelo teste $\mathrm{F}$ a $1 \%$; ns = não significativo. SAL = níveis de salinidade; $\mathrm{BIOF}=$ doses de biofertilizante; $\mathrm{CV}=$ coeficiente de variação.

A massa seca total das plantas de sorgo cv. BRS Ponta Negra (Figura 1A) apresenta decréscimo de $10,7 \mathrm{~g}$ para cada incremento unitário da salinidade da água de irrigação, de modo que o menor valor de massa seca total foi de $85,68 \mathrm{~g}$ na maior salinidade aplicada, com redução total de $42 \%$ em relação ao valor obtido com a menor salinidade da água $\left(C E a=0,2 \mathrm{dS} \mathrm{m}^{-1}\right)$, que foi de $147,85 \mathrm{~g}$. Aishah et al. (2011), avaliando a resposta de crescimento de duas variedades de sorgo forrageiro à salinidade $(0 ; 5 ; 10 \mathrm{e}$ $15 \mathrm{dS} \mathrm{m}^{-1}$ ), encontraram redução na massa seca total com valores de 54,66 e 39,87 g planta $^{-1}$, respectivamente, nas $\mathrm{CEa}=0$ e $\mathrm{CEa}=15 \mathrm{dS} \mathrm{m}^{-1}$. Ao submeterem duas cultivares de sorgo a três níveis de salinidade $\left(5,2 ; 10,5\right.$ e $\left.23,1 \mathrm{dS}^{-1}\right)$ e aplicação de silício, Kafi et al. (2011) verificaram decréscimo na massa seca total das plantas de sorgo com o aumento da salinidade da água. Resultados de redução da massa seca total das plantas foram verificados por outros autores (Lacerda et al., 2011; Chaugool et al., 2013; Ambede et al., 2012; Coelho et al., 2014; Sun et al., 2014).
Na Figura 1B, verifica-se que a altura das plantas foi negativamente afetada pela salinidade crescente da água de irrigação, com decréscimo de 12 $\mathrm{cm}$ para cada incremento unitário da salinidade da água de irrigação. Deste modo, o menor valor de altura obtido $(88 \mathrm{~cm})$ foi na máxima salinidade aplicada $\left(\mathrm{CEa}=6,0 \mathrm{dS} \mathrm{m}^{-1}\right)$; e em relação ao menor nível de salinidade, houve redução total de $44 \%$ na altura das plantas. Desai et al. (2012), em dois genótipos de sorgo submetidos à salinidade crescente da água de irrigação, em condições de casa de vegetação, encontraram redução média de $94 \%$ na altura, nos dois genótipos avaliados, nos maiores níveis de salinidade aplicados (300 mM).

Quanto ao comportamento do diâmetro do colmo (Figura 1C), verifica-se decréscimo de apenas $10 \%$ nos níveis iniciais de salinidade da água de irrigação, atingindo o valor mínimo $(14,69 \mathrm{~mm})$ na salinidade igual a 3,7 dS $\mathrm{m}^{-1}$, e a partir deste nível, incremento de $5 \%$ até à máxima salinidade aplicada $(6 \mathrm{dS}$ $\mathrm{m}^{-1}$ ), com valor igual a $15,42 \mathrm{~mm}$, indicando, assim, uma possível adaptação do sorgo ao estresse salino. 
Outros autores também observaram efeito negativo da salinidade sobre a altura e o diâmetro de caule em várias espécies (Sousa et al., 2011; Matos et al., 2013; Nascimento et al., 2015). As plantas glicófitas, em geral, sob estresse salino, sofrem declínios nas trocas

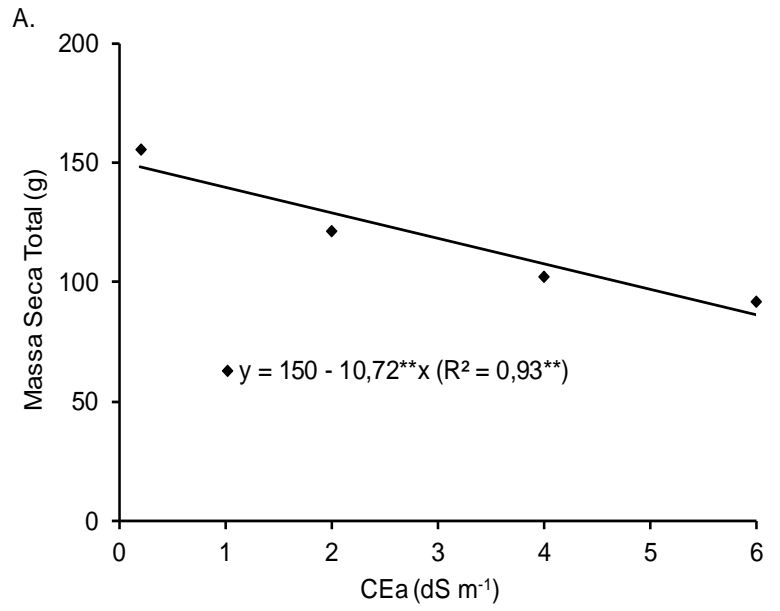

C.
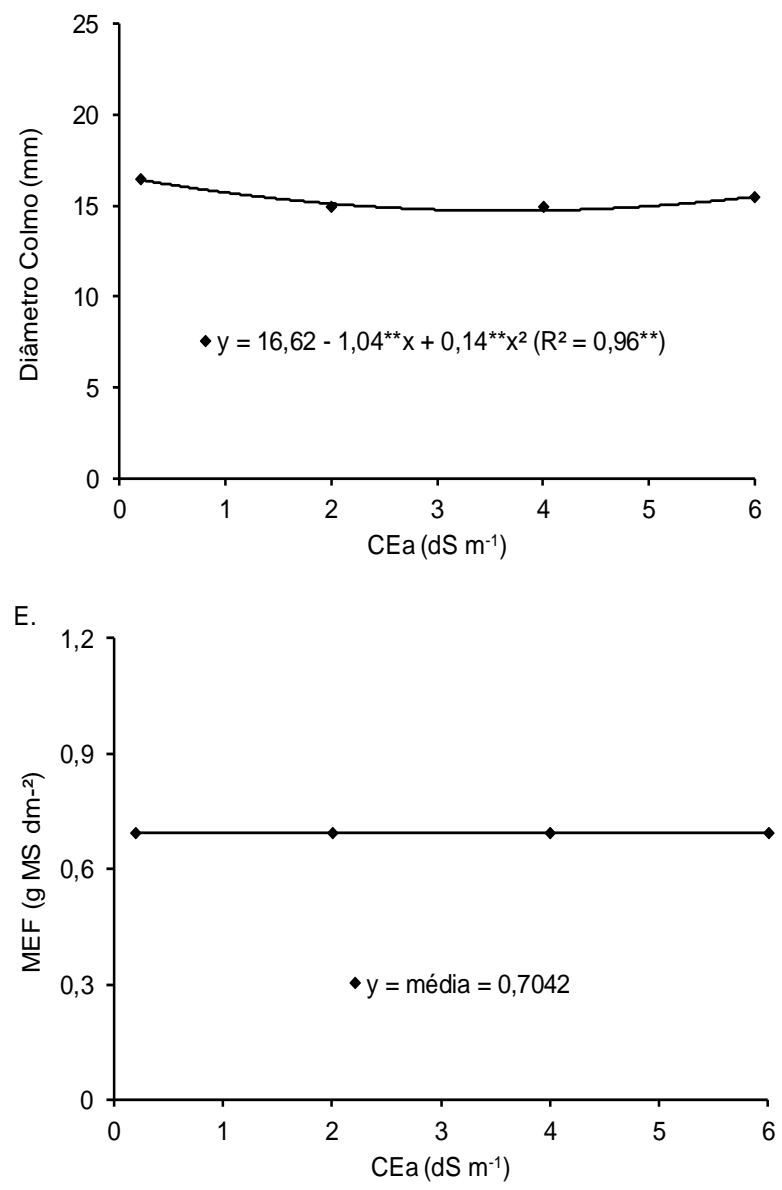

gasosas, eficiência fotossintética e produção de carboidratos, proteínas e outras substâncias vitais, como os ácidos nucleicos, com reflexos negativos no crescimento (Munns \& Tester, 2008).

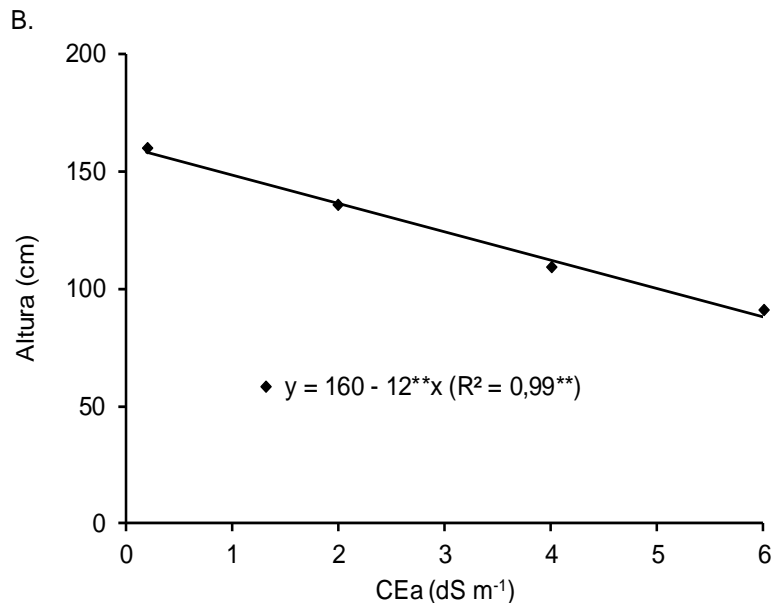

D.
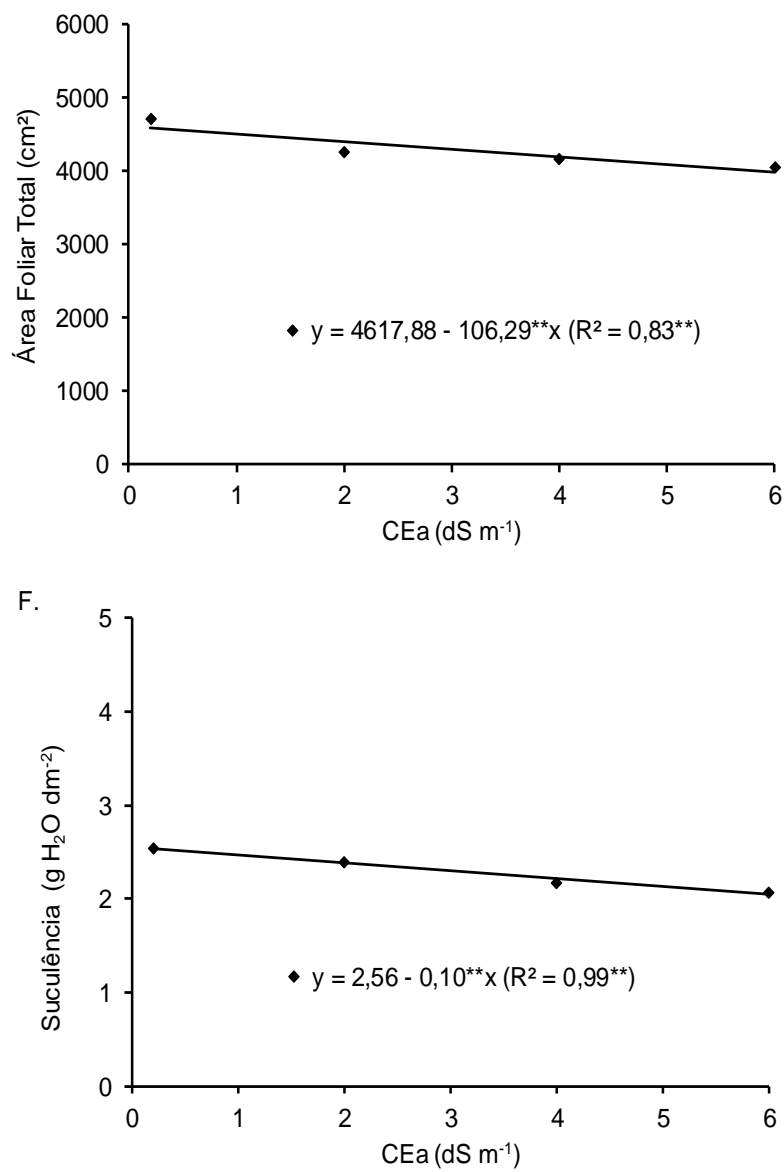

Figura 1 - Massa seca total de plantas (A), altura de plantas (B), diâmetro do colmo (C), área foliar total (D), massa específica foliar $(E)$ e suculência foliar $(F)$, nas plantas de sorgo cv. BRS Ponta Negra, em função da salinidade da água de irrigação. $\mathrm{CEa}=$ condutividade elétrica da água de irrigação. * Significativo pelo teste $\mathrm{F}$ a $5 \%$; ** Significativo pelo teste $\mathrm{F}$ a $1 \%$. Total dry mass of plants $(A)$, plant height $(B)$, culm diameter $(C)$, total leaf area (D), specific leaf mass (E) and leaf succulence (F) in sorghum $\mathrm{CV}$. BRS Ponta Negra, a function the salinity of the irrigation water. 
$\mathrm{Na}$ Figura 1D, observa-se que a área foliar total apresentou decréscimo de $106,3 \mathrm{~cm}^{2}$ por incremento unitário dos níveis de salinidade, com valor de 4.596,62 $\mathrm{cm}^{2}$ na menor salinidade $\left(\mathrm{CEa}=0,2 \mathrm{dS} \mathrm{m}^{-1}\right)$, e na maior salinidade $\left(\mathrm{CEa}=6,0 \mathrm{dS} \mathrm{m}^{-1}\right.$ ), o valor de área foliar total igual a $3.980,14 \mathrm{~cm}^{2}$, sendo verificada redução de $13 \%$ nesta variável. Vários estudos relatam efeito negativo da salinidade sobre o desenvolvimento foliar das culturas do sorgo (Sadeghi \& Shourijeh, 2012; Sun et al., 2014) e em outras espécies (Ambede et al., 2012; Sousa et al., 2012a). A área foliar é uma das variáveis de crescimento vegetal mais afetadas pela salinidade, pois sob estresse salino, as plantas apresentam redução na transpiração e na taxa de assimilação líquida de $\mathrm{CO}_{2}$ provocada pelo fechamento dos estômatos, em resposta ao baixo potencial da água do solo devido à elevada concentração salina (Silva et al., 2014); portanto, o crescimento foliar reduzido pode representar um mecanismo de defesa das plantas sob condições de estresse hídrico e salino, reduzindo as perdas de água por transpiração (Taiz \& Zeiger, 2009). Porém, o desenvolvimento das plantas é afetado à medida que a área foliar é reduzida, em virtude da menor capacidade fotossintética da planta como um todo (Falqueto et al., 2010) e, consequentemente, menor acúmulo de massa seca (Ambede et al., 2012), como verificado nesta pesquisa. $\mathrm{Na}$ Figura 1E, observa-se que a massa específica foliar não se ajustou a nenhum modelo quando se incrementou a salinidade da água de irrigação. Este resultado é um indicativo de que não foi verificado aumento da espessura do mesófilo e das paredes celulares, induzido pelo estresse salino, como verificado em outras espécies (Sousa et al., 2010). O incremento da massa específica foliar pelo aumento na espessura do mesófilo pode favorecer a assimilação de carbono por unidade de área foliar (Boote \& Tollenaar, 1994) e representa um mecanismo de aclimatação ao estresse salino (Trindade et al., 2006).

Verifica-se, na Figura $1 \mathrm{~F}$, que a suculência foliar reduziu $0,10 \mathrm{~g} \mathrm{H}_{2} \mathrm{O} \mathrm{dm}{ }^{-2}$, com o incremento unitário da salinidade da água de irrigação, com valor mínimo de $1,96 \mathrm{~g} \mathrm{H}_{2} \mathrm{O} \mathrm{dm} \mathrm{dm}^{-2}$ na maior salinidade aplicada, CEa $=6,0 \mathrm{dS} \mathrm{m} \mathrm{m}^{-1}$; portanto, com redução total de $23 \%$ em relação ao valor obtido na menor salinidade $\left(\mathrm{CEa}=0,2 \mathrm{dS} \mathrm{m}^{-1}\right)$, que foi de $2,54 \mathrm{~g} \mathrm{H}_{2} \mathrm{O} \mathrm{dm}{ }^{-2}$. $\mathrm{A}$ suculência foliar é um importante parâmetro para se identificar espécies tolerantes à salinidade e constitui uma das estratégias para a sobrevivência das plantas em condições de ambiente salino (Flowers \& Colmer, 2008), visto que o aumento da suculência tende a reduzir as concentrações de íons intracelulares e, assim, a evitar o acúmulo excessivo de íons na seiva das folhas (Sucre \& Suarez, 2011).

O acúmulo de íons de sódio dentro dos vacúolos reduz os níveis tóxicos de sódio no citosol e aumenta o potencial osmótico vacuolar com a geração concomitante de um potencial hídrico mais negativo, que favorece a absorção de água pela célula, e melhor retenção de água nos tecidos sob altos níveis de sali- nidade (Hamed et al., 2014; Maathuis, 2014). A redução da suculência foliar em plantas de sorgo, devido à salinidade da água de irrigação, foi constatada antes por diversos autores (Aquino et al., 2007; Sousa et al., 2010); vale salientar que aumento da suculência não é observada em sorgo (Trindade et al., 2006), possivelmente por ser uma caraterística mais comum nas plantas halófitas (Lokhande et al., 2011).

Observa-se, na Tabela 5, que houve efeito isolado das doses de biofertlizantes nas variáveis altura das plantas, diâmetro do colmo, área foliar total e massa específica foliar. Verifica-se, na Figura $2 A$, que a altura das plantas descresceu linearmente com o aumento das doses de biofertilizantes aplicadas, ao passo que o diâmetro do colmo + bainhas não se ajustou a nenhum modelo matemático (Figura 2B). A área foliar total (Figura $3 \mathrm{C}$ ) apresentou um leve crescimento, nos níveis iniciais do biofertilizante, atingindo seu máximo na dose de $153 L$ ha $^{-1}$ e posterior decréscimo até à máxima dose de biofertilizante aplicada (300 L ha-1). A massa específica foliar apesentou aumento de $10,2 \%$ quando se incrementaram as doses de biofertilizante (Figura 2D).

Sousa et al. (2012b), avaliando a aplicação de doses de biofertilizantes em milho, encontraram efeito significativo do biofertilizante nas variáveis altura das plantas, diâmetro caulinar, área foliar e massa seca total com comportamento positivo, com o aumento das doses do biofertilizante. Mesquita et al. (2010) concluíram que, na presença do biofertilizante bovino, 65 dias após a emergência de plantas de maracujazeiro-amarelo, a MST foi significativamente superior quando comparada à ausência do insumo orgânico. Neetu et al. (2014), verificando a aplicação de biofertilizante combinado com adubação nitrogenada, em sorgo forrageiro, encontraram efeito positivo em todas as características morfológicas estudas, com a aplicação da maior concentração de biofertilizante.

Os biofertilizantes possuem a capacidade de acelerar determinado processo microbiano para aumentar a extensão da disponibilidade de nutrientes numa forma que pode ser assimilado pela planta (Mohammadi \& Sohrabi, 2012); entretanto, a maior importância do biofertilizante como fertilizante não está nos quantitativos de seus nutrientes, mas na diversidade da composição mineral, que pode formar compostos quelatizados e serem disponibilizados pela atividade biológica e como ativador enzimático do metabolismo vegetal (Lacerda et al., 2010).

\section{Avaliação da composição mineral}

$\mathrm{Na}$ Tabela 6 , observa-se que os teores de cloro $(\mathrm{Cl})$, sódio $(\mathrm{Na})$, potássio $(\mathrm{K})$, cálcio $(\mathrm{Ca})$, magnésio $(\mathrm{Mg})$ e fósforo $(\mathrm{P})$ foram influenciados pela salinidade da água de irrigação ( $p<0,01$ ou $p<0,05)$, tanto nos colmos + bainhas quanto nos limbos foliares, excetuando a variável fósforo nos limbos foliares $(p>0,05)$. As doses de biofertilizante também afetaram os teores de minerais nos colmos + bainhas e limbos foliares $(p<0,01$ ou $p<0,05)$, exceto o teor 
de $\mathrm{K}$ e Mg nos colmos + bainhas e o teor de $\mathrm{Na}$ e $\mathrm{Mg}$ nos limbos foliares $(p>0,05)$. Já a interação entre os fatores afetou somente os teores de sódio e cloro no

A.
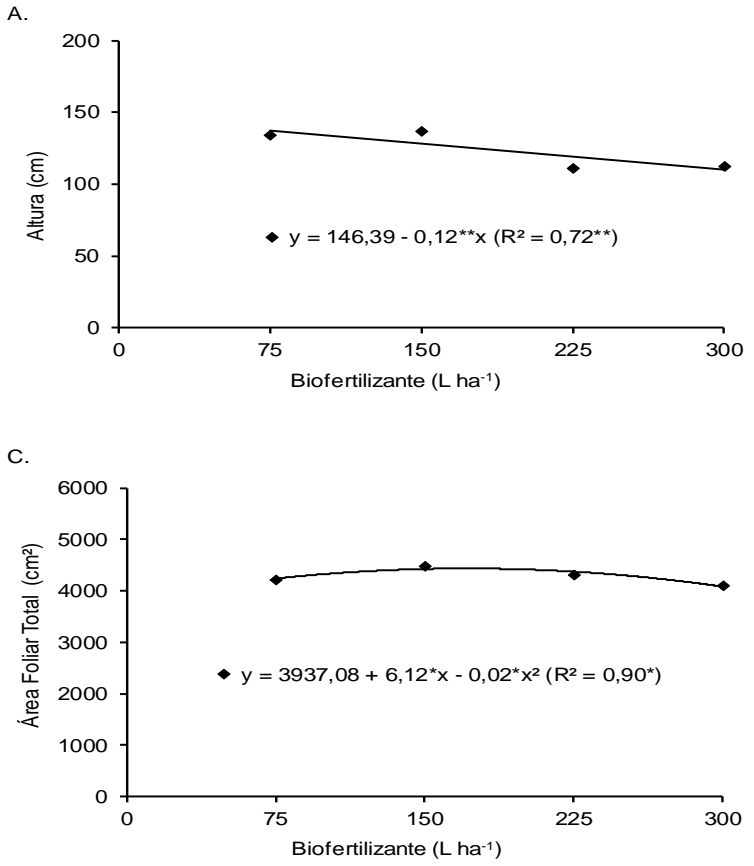

colmo + bainhas e limbos foliares, e o teor de $P$ nos limbos foliares $(p<0,05)$ e as demais variáveis não apresentaram significância estatística $(p>0,05)$.
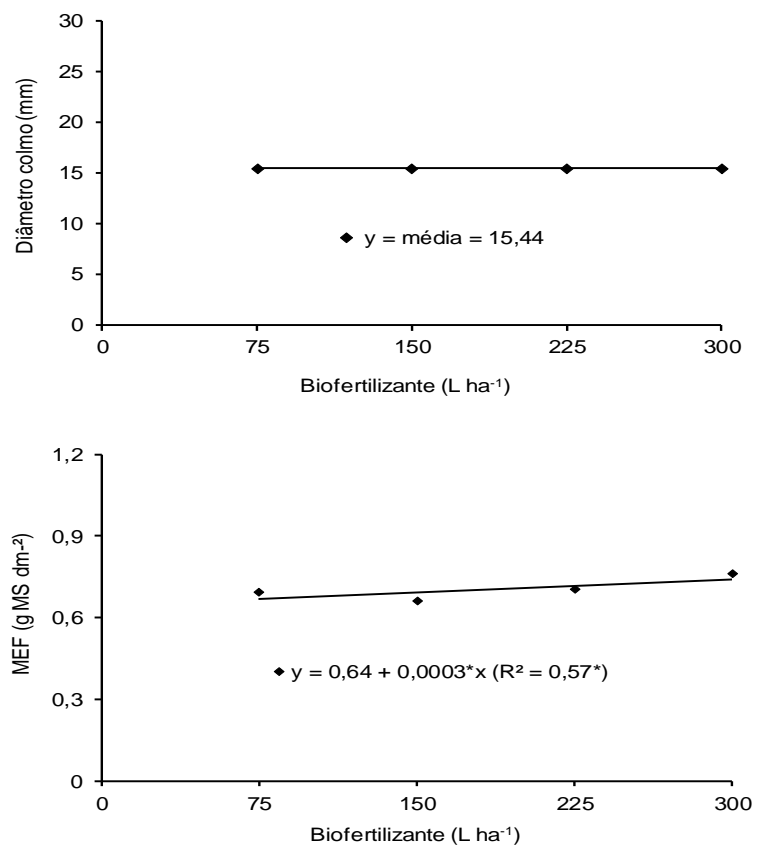

Figura 2 - Altura de plantas (A), diâmetro do colmo (B), área foliar total (C), massa específica foliar - MEF - (D) nas plantas de sorgo cv. BRS Ponta Negra, em função das doses de biofetlizante. * Significativo pelo teste $\mathrm{F}$ a $5 \%$; ${ }^{\star *}$ Significativo pelo teste $\mathrm{F}$ a $1 \%$. Plant height $(A)$, culm diameter $(B)$, total leaf area $(C)$ and specific leaf mass - MEF- (D) in sorghum cv. BRS Ponta Negra, as a function the biofertilizer dosis.

Tabela 6 - Valores do quadrado médio e significância estatística para sódio $(\mathrm{Na})$, cloro $(\mathrm{Cl})$, potássio $(\mathrm{K})$, fósforo $(\mathrm{P})$, cálcio $(\mathrm{Ca})$ e magnésio $(\mathrm{Mg})$ nos colmos + bainhas e limbos foliares de plantas de sorgo cv. BRS Ponta Negra, submetidas a diferentes doses de biofertilizante e irrigadas com água salobra. Mean square values and statistical significance for sodium ( $\mathrm{Na})$, chlorine (Cl), potassium $(K)$, phosphorus $(P)$, calcium (Ca) and magnesium (Mg) leaves and culms + sheath of sorghum cv. BRS Ponta Negra, submitted to different biofertilizer dosis and irrigated with saline water

\begin{tabular}{|c|c|c|c|c|c|c|}
\hline \multirow{3}{*}{ Fontes de Variação } & \multicolumn{6}{|c|}{ Quadrados médios } \\
\hline & \multicolumn{6}{|c|}{ Colmo + bainhas } \\
\hline & $\mathrm{Na}$ & $\mathrm{Cl}$ & $\mathrm{K}$ & $P$ & $\mathrm{Ca}$ & $\mathrm{Mg}$ \\
\hline SAL & $55,8577^{\star \star}$ & $109,97^{\star \star}$ & $11,9166^{\star \star}$ & $0,008^{* *}$ & $9,9016^{\star \star}$ & $13,028^{\star \star}$ \\
\hline BIOF & $0,9111^{\star *}$ & $186,00^{\star *}$ & $2,9233^{\text {ns }}$ & $0,006^{* *}$ & $3,5766^{\star}$ & $0,059^{\text {ns }}$ \\
\hline $\mathrm{SAL} \times \mathrm{BIOF}$ & $0,4041^{\star *}$ & $74,36^{\star *}$ & $1,1495^{\mathrm{ns}}$ & $0,002^{n s}$ & $1,5505^{\mathrm{ns}}$ & $0,377^{\text {ns }}$ \\
\hline RESIDUO & 0,1377 & 5,02 & 1,1833 & 0,001 & 0,9216 & 0,463 \\
\hline $\mathrm{CV}(\%)$ & 17,15 & 15,69 & 18,29 & 18,64 & 16,66 & 5,08 \\
\hline Fontes de Variação & \multicolumn{6}{|c|}{ Limbos foliares } \\
\hline SAL & $3,5596^{\star *}$ & $130,32^{* *}$ & $0,0425^{\star \star}$ & $0,004^{\text {ns }}$ & $44,6783^{\star *}$ & $37,188^{* *}$ \\
\hline BIOF & $0,0985^{\text {ns }}$ & $120,54^{* *}$ & $0,0102^{* *}$ & $0,026^{\star}$ & $11,4108^{* *}$ & $2,999^{\text {ns }}$ \\
\hline $\mathrm{SAL} \times \mathrm{BIOF}$ & $0,0945^{\star}$ & $9,31^{* *}$ & $0,0019^{\text {ns }}$ & $0,004^{\mathrm{ns}}$ & $1,9094^{\mathrm{ns}}$ & $4,493^{\text {ns }}$ \\
\hline RESIDUO & 0,0382 & 2,92 & 0,0013 & 0,006 & 0,9678 & 2,422 \\
\hline CV (\%) & 22,6 & 8,74 & 8,58 & 13,41 & 7,87 & 10,75 \\
\hline
\end{tabular}


$\mathrm{Na}$ Figura 3A, verifica-se, com a dose de $75 \mathrm{~L}$ ha $^{-1}$, decréscimo de $20 \%$ no teor de sódio no colmo + bainhas, nos níveis iniciais de salinidade até à salinidade de $1,12 \mathrm{dS} \mathrm{m}^{-1}$, com valor mínimo igual a $0,677 \mathrm{~g}$ $\mathrm{kg}^{-1}$; e a partir deste nível, incremento de $87 \%$ até à máxima salinidade aplicada $\left(\mathrm{CEa}=6,0 \mathrm{dS} \mathrm{m}^{-1}\right)$, obtendo-se valor igual a $5,43 \mathrm{~g} \mathrm{~kg}^{-1}$. Com a dose de $150 \mathrm{~L} \mathrm{ha}^{-1}$, nos primeiros níveis de salinidade, o teor de sódio no colmo + bainhas apresenta redução de $14 \%$, atingindo o menor valor $\left(0,649 \mathrm{~g} \mathrm{~kg}^{-1}\right)$ na $\mathrm{CEa}=1,07 \mathrm{dS} \mathrm{m}^{-1}$, e a partir deste nível, aumento de $84 \%$ até a CEa $=6,0 \mathrm{dS} \mathrm{m}^{-1}$, com valor de sódio no colmo + bainhas igual a $4,05 \mathrm{~g} \mathrm{~kg}^{-1}$. A dose de $225 \mathrm{~L} \mathrm{ha}^{-1}$ apresenta aumento de $0,7 \mathrm{~g} \mathrm{~kg}^{-1}$ no teor de sódio no colmo + bainhas, para cada incremento unitário da salinidade da água de irrigação, atingindo o maior valor $\left(4,47 \mathrm{~g} \mathrm{~kg}^{-1}\right)$ na maior salinidade, representando incremento total de $93 \%$, em relação ao valor encontrado no menor nível de salinidade $\left(\mathrm{CEa}=0,2 \mathrm{dS} \mathrm{m}^{-1}\right)$, que foi de $0,294 \mathrm{~g} \mathrm{~kg}^{-1}$. Por fim, verifica-se que a dose de $300 \mathrm{~L}^{2} \mathrm{ha}^{-1}$ reduz em $5 \%$ o valor do íon sódio no colmo + bainhas, nos primeiros níveis de salinidade, atingindo na salinidade igual a $0,71 \mathrm{dS} \mathrm{m}^{-1}$ seu valor mínimo $\left(0,649 \mathrm{~g} \mathrm{~kg}^{-1}\right)$, e posterior incremento de $86 \%$ até ao nível de maior salinidade aplicada, com valor igual a $4,56 \mathrm{~g} \mathrm{~kg}^{-1}$.

Nos limbos foliares (Figura 3B), o teor de sódio, com a aplicação de menor dose de biofertilizante (75 L ha-1), apresenta decréscimo de $30 \%$ nos menores níveis de salinidade, atingindo o valor mínimo de $0,458 \mathrm{~g} \mathrm{~kg}^{-1}$, na CEa $=1,86 \mathrm{dS} \mathrm{m}^{-1}$, e a partir deste nível aumento de $30 \%$ deste íon até à máxima salinidade $\left(\mathrm{CEa}=6,0 \mathrm{dS} \mathrm{m}^{-1}\right)$, com valor igual a 1,66 $\mathrm{dS} \mathrm{m}^{-1}$. $\mathrm{Na}$ dose de $150 \mathrm{~L} \mathrm{ha}^{-1}$, o valor de sódio nos limbos foliares, a partir dos níveis iniciais de salinidade, diminui $16 \%$ até à salinidade igual a $2,0 \mathrm{dS} \mathrm{m}^{-1}$, com valor mínimo de $0,52 \mathrm{~g} \mathrm{~kg}^{-1}$, e posterior incremento de $48 \%$ até à salinidade igual a $6,0 \mathrm{dS} \mathrm{m}^{-1}$, com valor igual a $1,00 \mathrm{~g} \mathrm{~kg}^{-1}$. Observa-se decréscimo de $22 \%$, nos níveis iniciais de salinidade, com a aplicação da dose de $225 \mathrm{~L} \mathrm{ha}^{-1}$ no teor de sódio dos limbos foliares até CEa $=1,9 \mathrm{dS} \mathrm{m}^{-1}$, com valor mínimo igual a $0,519 \mathrm{~g}$ $\mathrm{kg}^{-1}$, e a partir deste nível, aumento de $62 \%$ no teor de sódio até à máxima salinidade aplicada $\left(6,0 \mathrm{dS} \mathrm{m}^{-1}\right)$, obtendo-se $\circ$ valor de $1,36 \mathrm{dS} \mathrm{m}^{-1}$. A dose de $300 \mathrm{~L} \mathrm{ha}^{-1}$ apresenta redução de $35 \%$ do íon sódio nos limbos foliares, nos primeiros níveis de salinidade até atingir a $\mathrm{CEa}=1,9 \mathrm{dS} \mathrm{m}^{-1}\left(0,519 \mathrm{~g} \mathrm{~kg}^{-1}\right)$, quando, a partir deste nível, observa-se incremento de $75 \%$, até atingir a salinidade máxima $\left(6,0 \mathrm{dS} \mathrm{m}^{-1}\right)$, com o valor de $1,76 \mathrm{~g} \mathrm{~kg}^{-1}$.

Silva et al. (2011), estudando a aplicação de água salina na cultura do feijão-de-corda, com e sem aplicação de biofertilizante bovino, observaram aumento do teor do íon sódio, com maior acúmulo no caule que nas folhas, mediante a aplicação do biofertilizante. Sem a aplicação de biofertilizante, existem trabalhos que evidenciam que o acúmulo de íon sódio no colmo e nas folhas é comum em plantas de sorgo (Chaugool et al., 2013; Coelho et al., 2014) e em outras espécies (Kasrati et al., 2014), principalmente com a retenção maior no colmo que nas folhas, evidenciando a capacidade do sorgo de restringir o transporte de íons $\mathrm{Na}^{+}$e $\mathrm{Cl}^{-}$para as folhas, diminuindo a carga de sal nas folhas (Taiz \& Zeiger, 2009). No presente trabalho, verificou-se que as plantas, mesmo com a aplicação do biofertilizante, não evitaram o acúmulo do íon sódio, apenas promoveram a compartimentalização deste íon, sugerindo ser uma característica inerente à espécie, como forma de sobrevivência em um ambiente salino (Munns, 2002).

Verifica-se, na Figura 3C, incremento de $41 \%$ no teor do íon cloro no colmo + bainhas, com a aplicação da dose de $75 \mathrm{~L} \mathrm{ha}^{-1}$, até à salinidade $3,96 \mathrm{dS} \mathrm{m}^{-1}$, com valor máximo de $22,96 \mathrm{~g} \mathrm{~kg}^{-1}$, e a partir deste nível, decréscimo de $12 \%$ na maior salinidade $\left(\mathrm{CEa}=6,0 \mathrm{dS} \mathrm{m}^{-1}\right)$, com valor igual a $20,24 \mathrm{~g} \mathrm{~kg}^{-1}$. Comportamento semelhante verifica-se com a dose de $150 \mathrm{~L} \mathrm{ha}^{-1}$, com incremento de $54 \%$ do íon cloro no colmo + bainhas, atingindo o valor máximo $\left(19,66 \mathrm{~g} \mathrm{~kg}^{-1}\right)$ na $\mathrm{CEa}=3,37 \mathrm{~g} \mathrm{~kg}^{-1}$, e posterior decréscimo de $37 \%$ até à salinidade máxima, com valor de $12,38 \mathrm{~g} \mathrm{~kg}^{-1}$. As doses de 225 e $300 \mathrm{~L} \mathrm{ha}^{-1}$ apresentaram comportamento variado com o aumento da salinidade para o íon cloro no colmo + bainhas, representado por modelo cúbico de regressão. Nos limbos foliares (Figura 3D), verifica-se que, com a aplicação da dose de $75 \mathrm{~L} \mathrm{ha}^{-1}$ de biofertilizante, houve incremento de $1,61 \mathrm{~g} \mathrm{~kg}^{-1}$ do íon cloro para cada incremento unitário da salinidade, atingindo o maior valor $\left(28,06 \mathrm{~g} \mathrm{~kg}^{-1}\right)$ na maior salinidade aplicada, representando incremento total de $50 \%$ em relação à menor salinidade $\left(\mathrm{CEa}=0,2 \mathrm{dS} \mathrm{m}^{-1}\right)$, cujo valor foi igual a $18,72 \mathrm{~g} \mathrm{~kg}^{-1}$. Com a aplicação da dose de $150 \mathrm{~L} \mathrm{ha}^{-1}$, o teor de cloro nos limbos foliares não se ajustou a nenhum modelo de regressão, em função da salinidade da água, com média igual a $19,89 \mathrm{~g} \mathrm{~kg}^{-1}$. Com a aplicação da dose de $225 \mathrm{~L} \mathrm{ha}^{-1}$, verifica-se incremento de $1,28 \mathrm{~g} \mathrm{~kg}^{-1}$ por aumento unitário da salinidade, no teor de íon cloro nos limbos foliares, com maior valor igual a $21,19 \mathrm{~g} \mathrm{~kg}^{-1}$, na máxima salinidade aplicada $\left(\mathrm{CEa}=6,0 \mathrm{dS} \mathrm{m}^{-1}\right)$, representando, assim, incremento total de $54 \%$ em relação ao valor obtido na menor salinidade $\left(\mathrm{CEa}=0,2 \mathrm{dS} \mathrm{m}^{-1}\right)$, que foi de $13,77 \mathrm{~g} \mathrm{~kg}^{-1}$. Observa-se que a dose de $300 \mathrm{~L} \mathrm{ha}^{-1}$ de biofertilizante, em função da salinidade da água, apresentou comportamento variado no teor de cloro nos limbos foliares, ajustando-se a um modelo cúbico de regressão.

Majid et al. (2012) encontraram, em três cultivares de alfafa, diferentes aumentos no teor de cloro com o incremento da salinidade, sendo observado que o maior acúmulo ocorreu nas folhas. O sorgo apresenta melhor eficiência em reter os íons potencialmente tóxicos, no colmo, evitando sua exportação e o acúmulo nos limbos foliares, contribuindo para a maior tolerância das plantas ao estresse salino (Munns, 2002; Aquino et al., 2007), sendo esse efeito bem mais evidente para $\circ \mathrm{Na}$ de que para $\circ \mathrm{Cl}$. No presente trabalho, observou-se que, na maior salinidade 
$\left(\mathrm{CEa}=6,0 \mathrm{dS} \mathrm{\textrm {m } ^ { - 1 }}\right)$, os teores de cloro foram maiores nos limbos foliares, em média $40 \%$, que nos colmos + bainhas, provavelmente pela ação das doses do biofertilizante. Elevados níveis de nutrientes em meios salinos e a manutenção da absorção poderiam levar ao acúmulo do nutriente nos tecidos, em consequên-

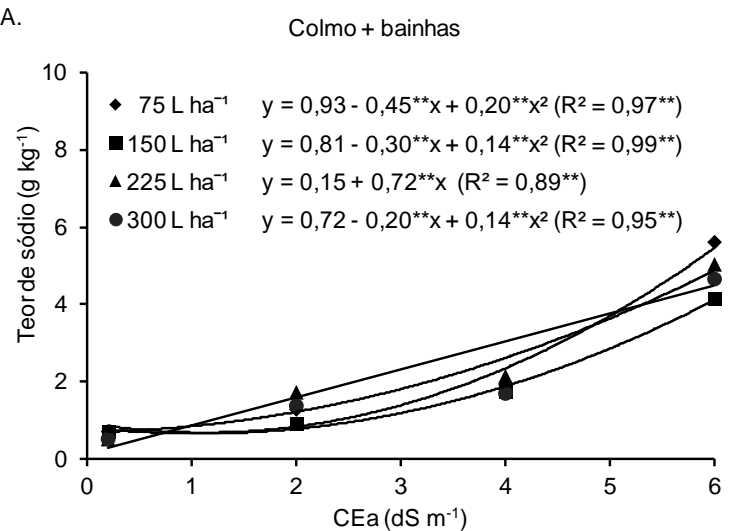

C.
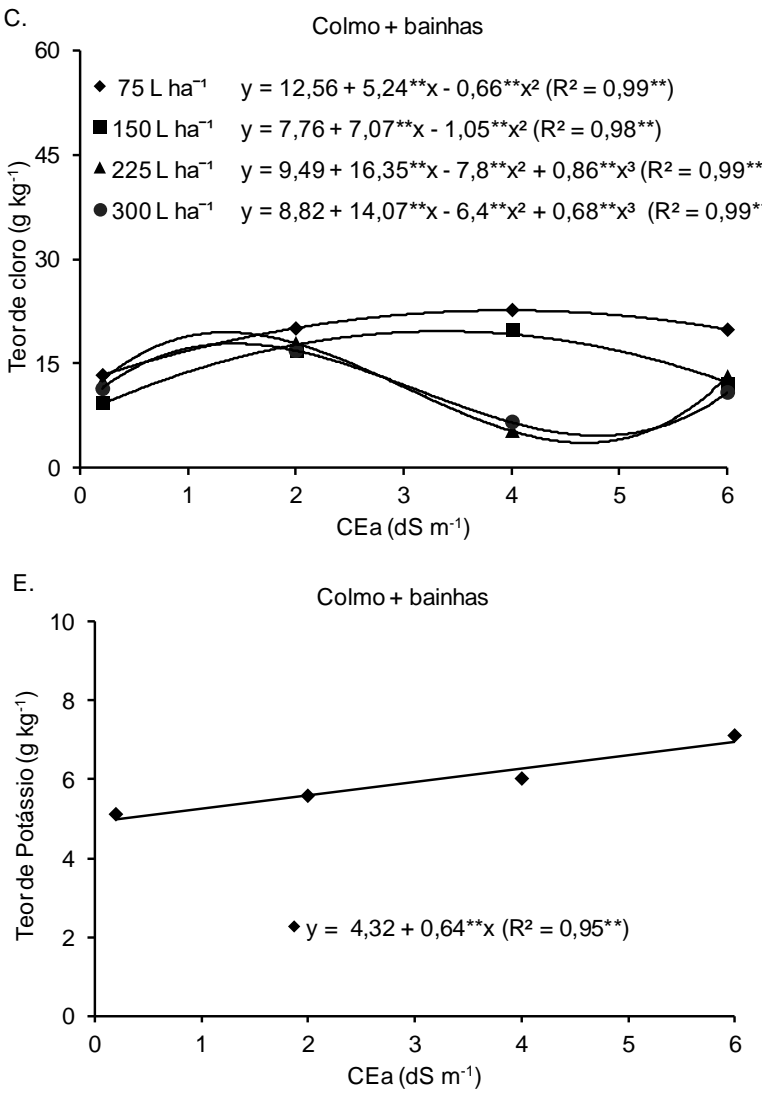

cia de um efeito de concentração, podendo resultar em uma falta de ajuste entre a aquisição e a assimilação de um determinado nutriente, acarretando toxidez e intensificando os efeitos deletérios causados pela salinidade (Lacerda et al., 2010).

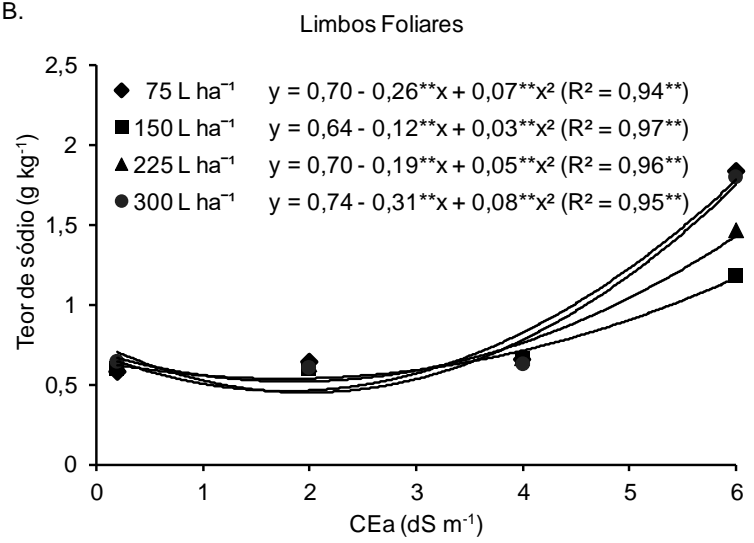

D.

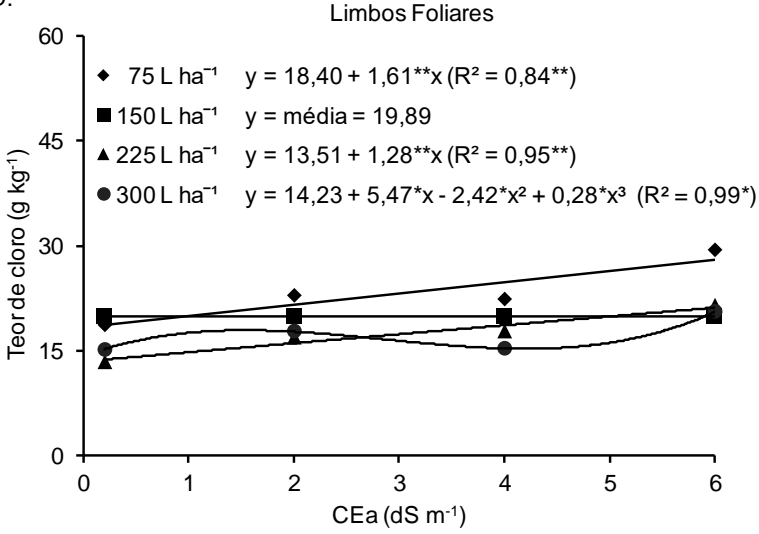

F.

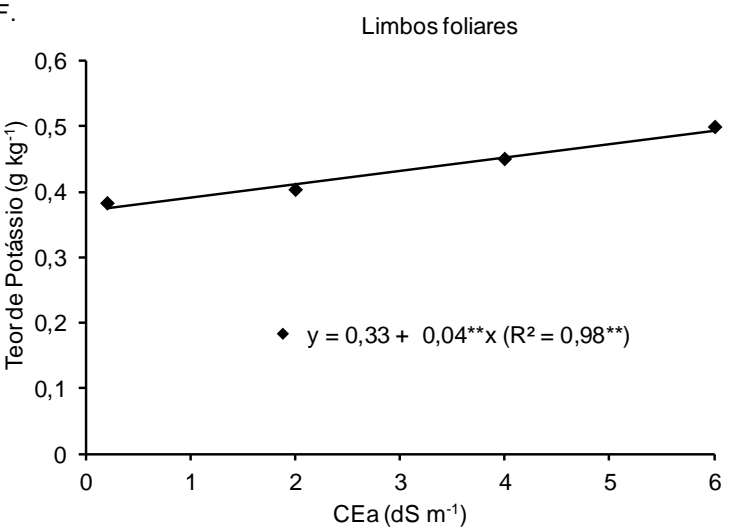

Figura 3 - Teor de sódio, cloro e potássio no colmo + bainhas (A, C e E) e nos limbos foliares (B, D e F) de plantas de sorgo cv. BRS Ponta Negra, em função da salinidade da água de irrigação. $\mathrm{CEa}=$ condutividade elétrica da água de irrigação. * Significativo pelo teste $\mathrm{F}$ a $5 \%$; ** Significativo pelo teste $\mathrm{F}$ a $1 \%$. Sodium, chlorine and potassium contents in culms + sheath $(A, C$ and $E)$ and leaves $(B, D$ and $F)$ of sorghum cv. BRS Ponta Negra as a function of the salinity of irrigation water. $\mathrm{CEa}=$ electrical conductivity of irrigation water. ${ }^{*}$ Significant by $5 \% \mathrm{~F}$ test; ** Significant by $F$ test at $1 \%$

Na Figura 3E, verifica-se que, no colmo + bainhas, o íon potássio aumentou $0,33 \mathrm{~g} \mathrm{~kg}^{-1}$ para cada incremento unitário da salinidade da água de irrigação, atingindo $\circ$ maior valor $\left(6,90 \mathrm{~g} \mathrm{~kg}^{-1}\right)$ na $\mathrm{CEa}=$ $=6,0 \mathrm{dS} \mathrm{m}^{-1}$, com $38 \%$ de incremento total em relação à menor salinidade da água $\left(\mathrm{CEa}=0,2 \mathrm{dS} \mathrm{m}^{-1}\right)$, cujo 
valor foi de $4,99 \mathrm{~g} \mathrm{~kg}^{-1}$. O mesmo comportamento foi observado nos limbos foliares (Figura 3F), pois o íon potássio aumentou $0,02 \mathrm{~g} \mathrm{~kg}^{-1}$ para cada unidade da salinidade da água de irrigação, apresentando o valor de $0,49 \mathrm{~g} \mathrm{~kg}^{-1}$ na $\mathrm{CE}=6,0 \mathrm{dS} \mathrm{m}^{-1}$, o que representa o incremento total de $31 \%$ em relação à menor salinidade da água de irrigação utilizada neste experimento. Tawfik et al. (2011) encontraram aumento de $\mathrm{K}$ em halófitas quando submetidas a salinidade crescente e aplicação de biofertilizante. Aquino et al. (2007) encontraram em plantas de sorgo, genótipo CSF 18, submetidas a salinidade, sem aplicação de biofertilizante, maior acúmulo do $\mathrm{K}^{+}$nos tecidos fotossintetizantes da planta, com valores no maior nível de salinidade $\left(\mathrm{CEa}=6,0 \mathrm{dS} \mathrm{m} \mathrm{m}^{-1}\right)$, igual a $10,86 \mathrm{~g} \mathrm{~kg}^{-1}$. Neste presente estudo, o íon potássio apresentou tendência de maior acúmulo no colmo, apesar do antagonismo que exerce com o íon sódio (Marschner, 1995; Parida \& Das, 2005), podendo ser explicado que, em condições de estresse salino, o melhor desempenho de certo genótipo pode estar relacionado com sua melhor nutrição potássica (Cekstere et al., 2015). Além disso, em solos salinos, a fração disponível de potássio $(\mathrm{K})$ pode aumentar através do aumento da CTC ligado ao teor de matéria orgânica (Diacono \& Montemurro, 2015). A diminuição ou o acréscimo do íon $\mathrm{K}$ pode ser influenciada pela duração do estresse bem como pela idade da folha amostrada.

$\mathrm{Na}$ Figura 4A, verifica-se que houve incremento no teor de cálcio nos colmos + bainhas de $0,06 \mathrm{~g} \mathrm{~kg}^{-1}$ a cada aumento unitário da salinidade da água de irrigação, com valor de $4,37 \mathrm{~g} \mathrm{~kg}^{-1}$ na menor salinidade $\left(\mathrm{CEa}=0,2 \mathrm{dS} \mathrm{m}^{-1}\right.$ ) e de $7,85 \mathrm{~g} \mathrm{~kg}^{-1}$ na maior salinidade $\left(\mathrm{CE}=6,0 \mathrm{dS} \mathrm{\textrm {m } ^ { - 1 }}\right.$ ), representando aumento de $79 \%$ no acúmulo deste íon. Nos limbos foliares (Figura 4B), houve aumento de $75 \%$ no teor de cálcio em relação à menor salinidade aplicada, com valores de 9,61 e 16,86 $\mathrm{g} \mathrm{kg}^{-1}$, respectivamente, nas $\mathrm{CE}=$ $=0,2 \mathrm{dS} \mathrm{m}^{-1}$ e CE $=6,0 \mathrm{dS} \mathrm{m}^{-1}$.

B.

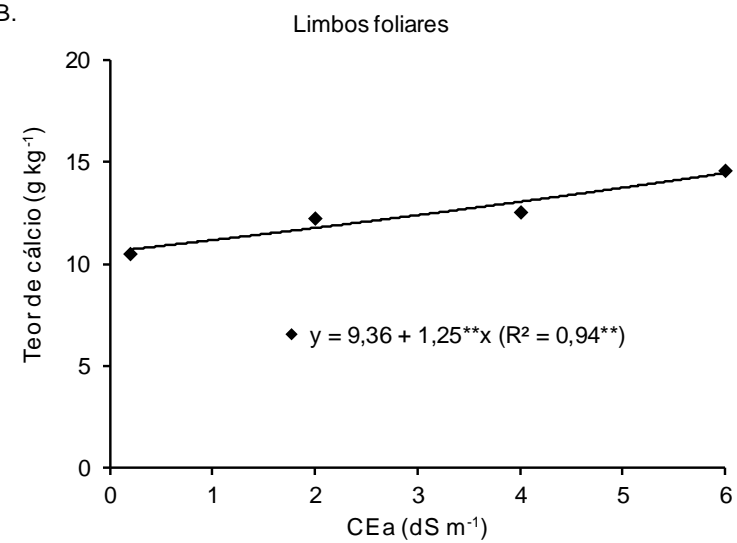

D.
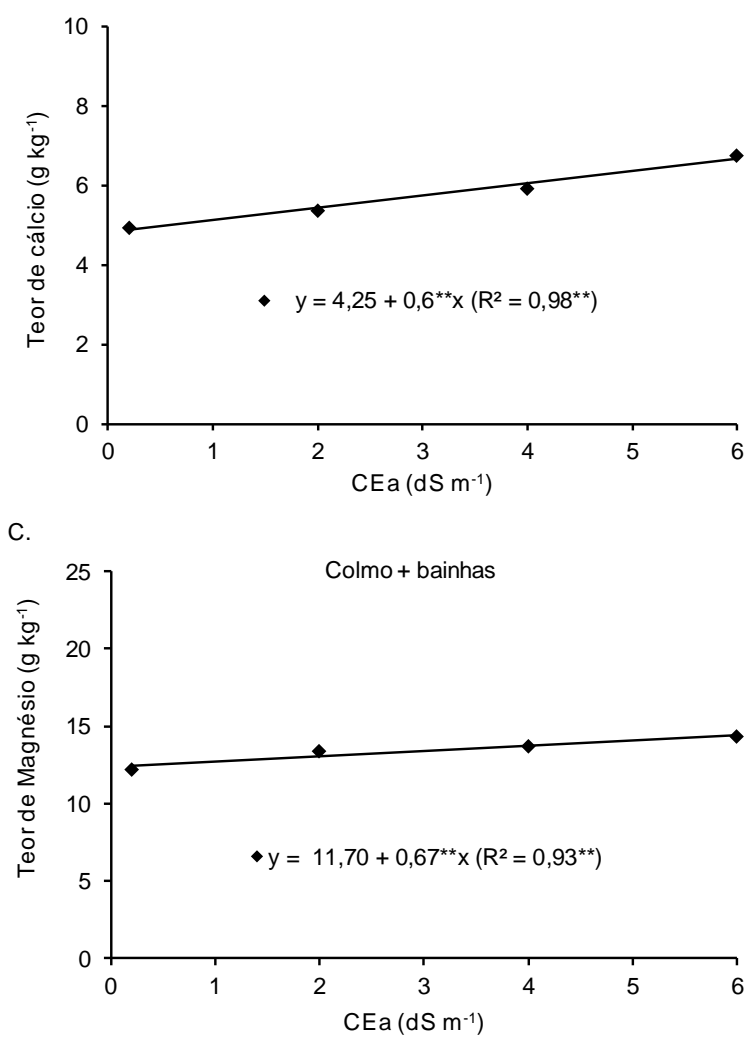

C.

Figura 4 - Teor de cálcio e magnésio no colmo + bainhas (A e C) e nos limbos foliares (B e D) de plantas de sorgo cv. BRS Ponta Negra em função da salinidade da água de irrigação. CEa = condutividade elétrica da água de irrigação. * Significativo pelo teste $\mathrm{F}$ a $5 \%$; ${ }^{*}$ Significativo pelo teste $\mathrm{F}$ a $1 \%$. Calcium and magnesium contents in culms + sheath $(A$ and $C)$ and leaves $(B$ and $D)$ of sorghum plants cv. BRS Ponta Negra as a function of the salinity of irrigation water. CEa = electrical conductivity of irrigation water. * Significant by $5 \%$ F test; ** Significant by $1 \%$ F test.

O aumento dos teores de cálcio pode ser atribuído aos altos teores deste íon na composição da água de irrigação (Tabela 1). Aumento de cálcio nas plantas com a salinidade também foi encontrado por outros autores (Morgan et al., 2014; Gengmao et al., 2015). Entretanto, Saberi \& Aishah (2013), analisando a resposta de sorgo forrageiro à salinidade crescente e à frequência de irrigação, verificaram diminuição de 
cálcio com o aumento da salinidade. Niu et al. (2012), avaliando diferentes genótipos de sorgo submetidos à salinidade, constataram que houve incremento de cloro e decréscimo de cálcio e magnésio nas plantas. Estas divergências indicam uma possível adapatação fisiológica da planta à salinidade, pois a maior acumulação de Ca pode contribuir na tolerância ao estresse salino, devido ao seu papel na manutenção da integridade das membranas. Haja vista a importância da seletividade das membranas nos processos de absorção e de compartimentação iônica (Azevedo Neto \& Tabosa, 2000).

Observa-se, na Figura 4C, que o teor de magnésio no colmo + bainhas apresentou incremento de $0,67 \mathrm{~g} \mathrm{~kg}^{-1}$ por aumento unitário da salinidade da água de irrigação, atingindo o maior valor $\left(15,72 \mathrm{~g} \mathrm{~kg}^{-1}\right)$ na maior salinidade, e em relação ao menor nível de salinidade, incremento total de $33 \%$. Comportamento semelhante foi verificado nos limbos foliares (Figura $4 \mathrm{D}$ ), pois para cada incremento unitário da salinidade ocorreu aumento de $1,15 \mathrm{~g} \mathrm{~kg}^{-1}$ no teor de magnésio, com maior valor observado $\left(18,49 \mathrm{~g} \mathrm{~kg}^{-1}\right)$ na salinidade máxima $\left(C E a=6,0 \mathrm{dS} \mathrm{m}^{-1}\right)$, e em relação ao menor nível de salinidade, $\mathrm{CEa}=0,2 \mathrm{dS} \mathrm{m}^{-1}$, houve $\mathrm{O}$ aumento total de $56 \%$ nos valores deste íon nos limbos foliares. $O$ aumento no teor de magnésio pode ser justificado pelo Mg contido na água de irrigação, haja vista que sua concentração era tanto maior quanto maior era também a CE da água de irrigação.

Contradizendo este trabalho, na literatura, encontram-se resultados de decréscimos nos teores de magnésio em plantas submetidas à salinidade (Guerrero-Rodríguez et al., 2011; Rady et al., 2011). E, corroborando este trabalho, na literatura, verifica-se aumento no teor de magnésio com a salinidade (Talaat \& Shawky, 2014). De acordo com Taiz \& Zeiger (2009), o magnésio, além de exercer papel na atividade como cofator em quase todas as enzimas do metabolismo energético e na molécula de clorofila, é um íon requerido para a integridade dos ribossomos e contribui efetivamente para a estabilidade estrutural dos ácidos nucleicos e membranas.

Observa-se, também, na Tabela 6, a ocorrência de efeitos isolados do biofertilizante sobre os teores de $\mathrm{P}$ e Ca no colmo + bainhas e sobre os teores de $\mathrm{K}, \mathrm{P}$ e Ca nos limbos foliares. Para o efeito isolado do biofertilizante sobre os teores nos limbos foliares, identifica-se aumento nos teores de K (Figura 5A) e Ca (Figura 5B) e redução no teor de $\mathrm{P}$ (Figura $5 \mathrm{C}$ ). Para os teores de $\mathrm{Ca}$ e $\mathrm{P}$ nos colmos + bainhas, as respostas não se ajustaram a nenhum modelo matemático (dados não mostrados), de modo que os resultados não indicam nenhuma tendência clara dos efeitos do biofertilizante sobre os teores desses nutrientes neste experimento.

A.

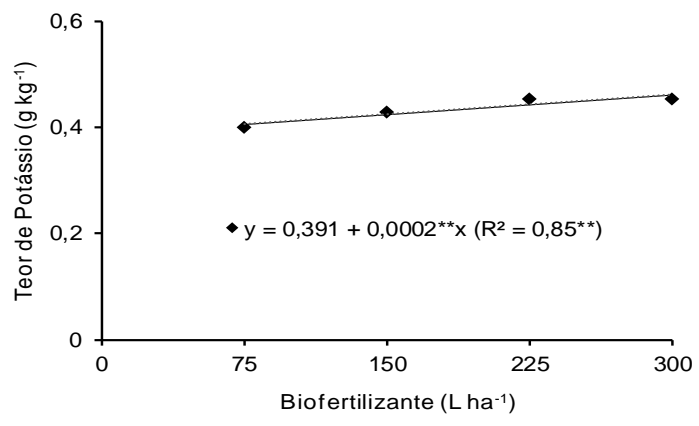

B.

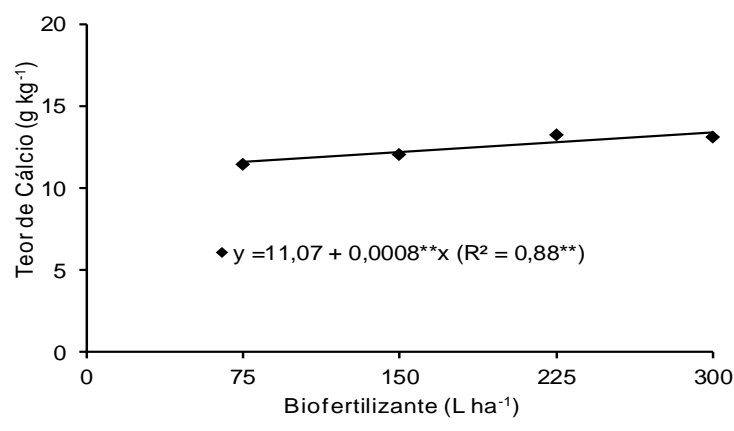

C.

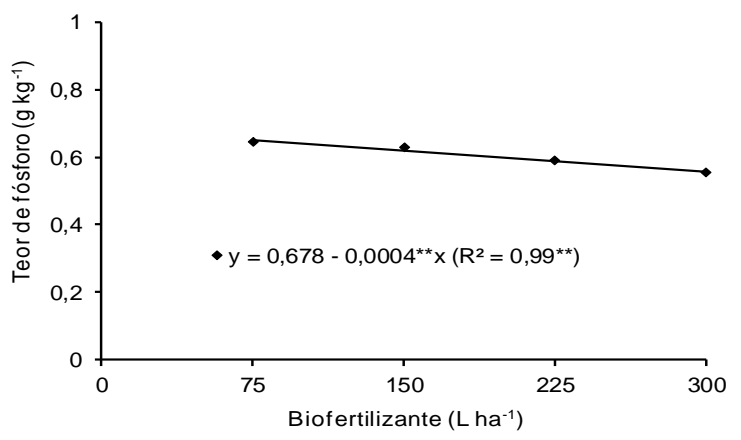

Figura 5 - Teor de potássio (A), cálcio (B) e fósforo (C)nos limbos foliares de plantas de sorgo cv. BRS Ponta Negra em função das doses de biofertilizante. $\mathrm{CEa}=$ condutividade elétrica da água de irrigação. * Significativo pelo teste $\mathrm{F}$ a $5 \%$; ** Significativo pelo teste $\mathrm{F}$ a $1 \%$. Potassium, calcium and phosphorus and contents in culms + sheath $(A, C$ and $E)$ and leaves ( $B, D$ and $F$ ) of sorghum cv. BRS Ponta Negra as a function of the biofertilizer dosis. ${ }^{*}$ Significant by $5 \% \mathrm{~F}$ test; ${ }^{*}{ }^{*}$ Significant by $\mathrm{F}$ test at $1 \%$. 
Silva et al. (2011) também encontraram aumentos nos teores de cálcio, tanto nas folhas quanto no caule, de feijão-de-corda, irrigado com níveis crescentes de sais e com aplicação de biofertilizante; no entanto, nas plantas que não foram biofertilizadas, apresentaram valores superiores de cálcio. Com relação ao fósforo, esses mesmos autores encontraram aumento nas folhas e no caule e concluíram que a presença de biofertilizante líquido bovino resultou em teores bem superiores de fósforo, em relação às plantas não supridas com esse insumo orgânico. Nascimento et al. (2011), estudando o efeito nutricional de maracujazeiro-amarelo, irrigado com água salina e com aplicação de biofertilizante, encon- traram incremento de cálcio nas plantas. Aquino (2005) encontrou aumento de fósforo em plantas de sorgo submetidas a estresse salino evidenciando a existência de interação entre salinidade e fósforo em plantas de sorgo.

\section{Análise dos solutos orgânicos}

Observa-se, na Tabela 7, que o teor de carboidratos e de prolina nas folhas foi influenciado significativamente pela salinidade da água de irrigação $(p<0,01)$, pelas doses do biofertilizante $(p<0,01)$ e pela interação entre esses dois fatores $(p<0,01)$.

Tabela 7 - Valores do quadrado médio e significância estatística para as variáveis carboidratos e prolina nas folhas de plantas de sorgo cv. BRS Ponta Negra, irrigadas com água salobra e submetidas a diferentes doses de biofertilizante. Mean square values and statistical significance for the carbohydrate and proline in leaves of sorghum cv. BRS Ponta Negra, irrigated with saline water and submitted to different of biofertilizer dosis.

\begin{tabular}{|c|c|c|}
\hline \multirow{2}{*}{ Fontes de Variação } & \multicolumn{2}{|c|}{ Quadrados médios } \\
\hline & Carboidratos & Prolina \\
\hline $\begin{array}{l}\text { SAL } \\
\text { BIOF }\end{array}$ & $\begin{array}{l}291.607,92^{\star *} \\
254.245,43^{\star *}\end{array}$ & $\begin{array}{r}139,78^{\star *} \\
37,15^{\star *}\end{array}$ \\
\hline $\mathrm{SAL} \times \mathrm{BIOF}$ & $145.363,39^{*}$ & $23,81^{* *}$ \\
\hline RESIDUO & $52.893,20$ & 7,24 \\
\hline CV (\%) & 15,34 & 19,00 \\
\hline
\end{tabular}

${ }^{*}$ Significativo pelo teste $\mathrm{F}$ a $5 \%$; ** Significativo pelo teste $\mathrm{F}$ a $1 \%$; ns= não significativo. $\mathrm{SAL}=$ níveis de salinidade da água de irrigação; $\mathrm{BIOF}=$ doses de biofertilizante; $\mathrm{CV}=$ coeficiente de variação.

Na Figura 6A, com o incremento da salinidade da água de irrigação, observa-se que os teores de carboidratos, nas doses de biofertilizantes de 150; 225 e $300 \mathrm{~L} \mathrm{ha}^{-1}$, não se ajustaram a nenhum modelo matemático, enquanto a dose de $75 \mathrm{~L}_{\text {ha-1 }}{ }^{-1}$ está representada por um modelo cúbico. Este resultado indica que $o$ aumento nos teores de carboidratos não pareceu ter contribuído significativamente para a manutenção de um potencial hídrico favorável à absorção de água, ou seja, para o ajustamento osmótico foliar. Parida \& Das (2005) afirmam que incremento de carboidratos sugere uma resposta da planta ao estresse, uma vez que seu acúmulo atua como osmoprotetor, reserva de carbono, além do combate aos radicais livres nas plantas. Vários autores encontraram acúmulo de carboidratos em plantas sob estresse salino (Nemati et al., 2011; Tang et al., 2013); porém outros verificaram que a tolerância à salinidade não estava relacionada ao conteúdo de carboidratos (Praxedes et al., 2011), enquanto outros autores verificaram que, mesmo sob salinidade elevada, o teor de carboidratos pode permanecer inalterado (Heidari, 2012) ou decrescer (Zhang et al., 2012).

Verifica-se, na Figura 6B, com a aplicação da dose de $75 \mathrm{~L} \mathrm{ha}^{-1}$ de biofertilizante, nos níveis iniciais de salinidade, incremento de $64 \%$ no teor de prolina, atingindo $o$ valor máximo, $16,49 \mu \mathrm{mol} \mathrm{g}{ }^{-1}$, na CEa $=$ $=4,05 \mathrm{dS} \mathrm{m}^{-1}$, e posterior declínio de $16 \%$ até à máxima salinidade aplicada $\left(\mathrm{CEa}=6,0 \mathrm{dS} \mathrm{m}^{-1}\right)$. $\mathrm{Na}$ dose de $150 \mathrm{~L} \mathrm{ha}^{-1}$, o aumento de $26 \%$ na prolina ocorre nos primeiros níveis de salinidade até à salinidade igual a 3,32 dS $\mathrm{m}^{-1}$, com ponto máximo de $18,38 \mu \mathrm{mol} \mathrm{g}^{-1}$, e a partir deste nível, redução de $19 \%$ na CEa $=6,0 \mathrm{dS} \mathrm{m}^{-1}$. Com a dose de $225 \mathrm{~L} \mathrm{ha}^{-1}$, observa-se incremento de $30 \%$ no teor de prolina, nos níveis iniciais de salinidade até à salinidade igual a $3,0 \mathrm{dS} \mathrm{m}^{-1}$, com valor máximo igual $17,83 \mu \mathrm{mol} \mathrm{g}^{-1}, \mathrm{e}$, logo em seguida, decréscimo de $34 \%$ verificado na maior salinidade aplicada. $\mathrm{Na}$ dose de $300 \mathrm{~L} \mathrm{ha}^{-1}$, o teor de prolina apresenta incremento de $40 \%$ nos primeiros níveis de salinidade, atingindo o valor máximo igual a $16,86 \mu \mathrm{mol} \mathrm{g}^{-1}$, na salinidade igual a $3,37 \mathrm{dS} \mathrm{m}^{-1}$, e posterior decréscimo de $28 \%$ na salinidade máxima aplicada ( $\mathrm{CEa}=6,0 \mathrm{dS} \mathrm{m}^{-1}$ ).

Resultados de acúmulos de prolina têm sido observados em plantas submetidas à salinidade crescente, tanto em cultivos sem aplicação de biofertilizante (Acosta-Motos et al., 2015; Zhao et al., 2015), como em ensaios com a aplicação desse insumo (Abdelhamid et al., 2010; Tawfik et al., 2011). O acúmulo de prolina é relatado como uma resposta aos estresses abióticos, além de haver uma relação positiva entre a prolina e a tolerância ao estresse salino nas plantas (Borgo et al., 2015). Em plantas de sorgo, no entanto, observou-se correlação inversa, sugerindo que a prolina quantificada nas folhas pode ser indicativo do dano provocado pelo estresse salino (Lacerda et al., 2003). 

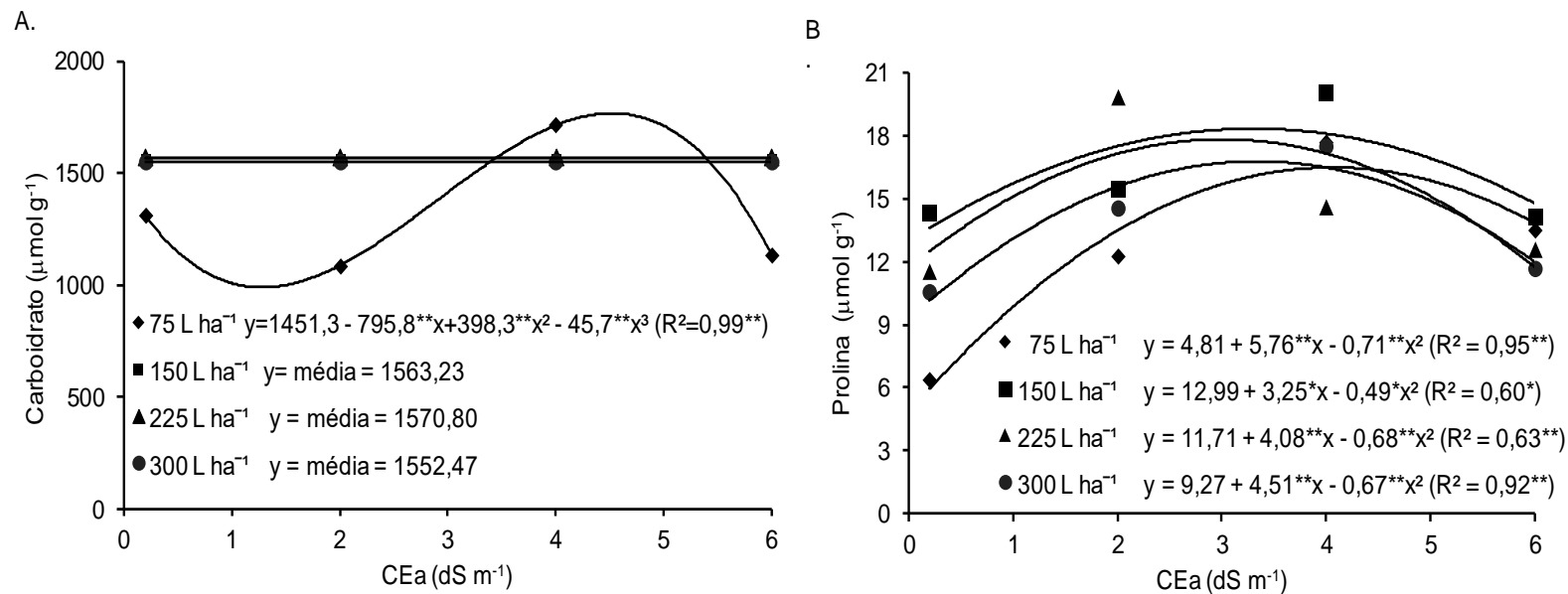

Figura 6 - Teor de carboidratos (A) e prolina (B) nas folhas de plantas de sorgo cv. BRS Ponta Negra em função da salinidade da água de irrigação. $\mathrm{CEa}=$ condutividade elétrica da água de irrigação. * Significativo pelo teste $\mathrm{F}$ a 5\%; ** Significativo pelo teste $\mathrm{F}$ a $1 \%$. Carbohydrates $(A)$ and proline $(B)$ in leaves of sorghum $\mathrm{Cv}$. BRS Ponta Negra as a function of the salinity of irrigation water. $C E a$ = electrical conductivity of irrigation water. ${ }^{*}$ Significant by $5 \%$ F test; ${ }^{* \star}$ Significant by $1 \%$ F test.

\section{Conclusões}

- Todas as variáveis de crescimento do sorgo cv. BRS Ponta Negra foram influenciadas negativamente pelos níveis crescentes de sais da água de irrigação, sendo que o aumento da concentração de biofertilizante, nos limites empregados no presente estudo, não minorou os efeitos da salinidade no crescimento das plantas.

- O acúmulo dos íons de $\mathrm{Na}, \mathrm{Cl}$ e $\mathrm{K}$ foi influenciado pela salinidade crescente da água de irrigação no colmo + bainhas e nos limbos foliares das plantas de sorgo, ocorrendo maior acúmulo de $\mathrm{Cl}$ nos limbos foliares e de $\mathrm{Na}$ e K nos colmos + bainhas.

- Houve maior acúmulo de P, Ca e Mg ao se incrementar a salinidade da água de irrigação, principalmente nos limbos foliares das plantas.

- Os teores de carboidratos nas folhas não sofreram variação acentuada com o aumento da salinidade da água de irrigação, enquanto houve acúmulo de prolina até à salinidade igual a $4,0 \mathrm{dS} \mathrm{m}^{-1}$.

\section{Agradecimentos}

À Coordenação de Aperfeiçoamento de Pessoal de Nível Superior (CAPES) e ao Instituto Nacional de Ciência e Tecnologia em Salinidade (INCTSal), pela contribuição para a realização deste trabalho.

\section{Referências}

Abdelhamid MT, Shokr M, Bekheta MA (2010) Growth, root characteristics, and leaf nutrients accumulation of four faba bean (Vicia faba L.) cultivars differing in their broomrape tolerance and the soil properties in relation to salinity. Communications in Soil Science and Plant Analysis 41(22):2713-2728.

10.1080/00103624.2010.518263
Acosta-Motos JR, Diaz-Vivancos $\mathrm{P}$, Álvarez $\mathrm{S}$, Fernández-García N, Sánchez-Blanco MJ, Hernández JA (2015) NaCl-induced physiological and biochemical adaptative mechanisms in the ornamental Myrtus communis L. plants. Journal of Plant Physiology 183:41-51. doi: 10.1016/j.jplph.2015.05.005

Ahamd M, Zahir ZA, Nadeem SM, Nazli F, Jamil M, Jamshaid MU (2014) Physiological response of mung bean to Rhizobium and Pseudomonas based biofertilizers under salinity stress. Pakistan Journal Agricultural Sciences 51(3):557-564.

Aquino AJS (2005) Avaliação do crescimento e de mecanismos de tolerância à salinidade em plantas de sorgo forrageiro irrigadas com águas salinas. UFC. (Dissertação de mestrado em Irrigação e Drenagem)

Aquino AJS, Lacerda CF, Bezerra MA, Gomes Filho E, Costa RNT (2007) Crescimento, partição de matéria seca e retenção de $\mathrm{Na}^{+}, \mathrm{K}^{+}$e $\mathrm{Cl}^{-}$em dois genótipos de sorgo irrigados com águas salinas. Revista Brasileira de Ciência do Solo 31(5):961-971. doi: 10.1590/S0100-06832007000500013

Ambede JG, Netondo GW, Mwai GN, Musyimi, DM (2012) $\mathrm{NaCl}$ salinity affects germination, growth, physiology, and biochemistry of bambara groundnut. Brazilian Journal Plant Physiology 24(3):151-160. doi: 10.1590/S1677-04202012000300002

Aishah S, Saberi HAR, Halim RA, Zaharah AR (2011) Yield responses of forage sorghums to salinity and irrigation frequency. African Journal of Biotechnology 10(20):4114-4120. doi: 10.5897/AJB10.2368

Ayers, R. S.; Westcot, D. W. 1999. A qualidade da água na agricultura. Trad. Gheyi, H. R.; Medeiros, J. F.; Damasceno, F. A. V. UFPB, 153p. 
Avelino PM, Neiva JNM, Araújo, VL, Alexandrino E, Santos AC, Restle J (2011) Características agronômicas e estruturais de híbridos de sorgo em função de diferentes densidades de plantio. Revista Çiência Agronômica 42(2):534-541.

Azevedo Neto AD, Tabosa JN (2000) Estresse salino em plântulas de milho: Parte II distribuição dos macronutrientes catiônicos e suas relações com o sódio. Revista Brasileira de Engenharia Agrícola e Ambiental 4(2):165-171.

Badar R, Batool B, Ansari A, Mustafa S, Ajmal A, Perveen S (2015) Amelioration of salt affected soils for cowpea growth by application of organic amendments. Journal of Pharmacognosy and Phytochemistry 3(6):87-90.

Bates LS, Waldren RP, Teare ID (1973) Rapid determination of free proline for water-stress studies. Plant and Soil 39(1):205-207.

Boote KJ, Tollenaar M (1994) Modeling genetic yield potential. In: Boote KJ, Bennett JM, Sinclair TR, Paulsen GM (eds) Physiology and determination of crop yield. American Society of Agronomy, p.553-565.

Borgo L, Marur CJ, Vieira, LGE (2015) Effects of high proline accumulation on chloroplast and mitochondrial ultrastructure and on osmotic adjustment in tobacco plants. Acta Scientiarum. Agronomy 37(2):191-199.

Cekstere G, Karlsons A, Grauda D (2015) Salinityinduced responses and resistance in Trifolium repens L. Urban Forestry \& Urban Greening 14(2):225-236.

Chaugool J, Naito H, Kasuga S, Ehara H (2013) Comparison of young seedling growth and sodium distribution among sorghum plants under salt stress. Plant Production Science 16(3):261-270.

Coelho DS, Simões WL, Mendes AMS, Dantas BF, Rodrigues JAS, Souza MA (2014) Germinação e crescimento inicial de variedades de sorgo forrageiro submetidas ao estresse salino. Revista Brasileira de Engenharia Agrícola e Ambiental 18(1):25-30.

Desai D, Khare T, Kumar V (2012) Sulfate and chloride salinity induced effects on physiological and biochemical parameters of sorghum. International Journal of Biochemistry and Biotechnology 1(2):5-10.

Diacono M, Montemurro F (2015) Effectiveness of organic wastes as fertilizers and amendments in saltaffected soils. Agriculture 5(2):221-230.

Dias NS, Cosme CR, Souza ACM, Silva MRF (2012) Gestão das águas residuárias provenientes da dessalinização da água salobra. In: Gheyi HR, Paz VPS,

Medeiros SS, Galvão CO (Eds) Recursos hídricos em regiões semiáridas: Estudos e aplicações, INSA, p.176-187.
Dubois M, Gilles KA, Hamilton JK, Rebers PA, Smith F (1956) Colorimetric method for determination of sugars and related substances. Analytical Chemistry 28(3):350-356. doi: 10.1021/ac60111a017

Falqueto, AR, Silva FSP, Cassol D, Magalhães Júnior AM, Oliveira AC, Bacarin MA (2010) Chlorophyll fluorescence in rice: probing of senescence driven changes of PSII activity on rice varieties differing in grain yield capacity. Brazilian Journal Plant Physiology 22(1):35-41. doi: 10.1590/S1677-04202010000100004.

Flowers TJ, Colmer TD (2008) Salinity tolerance in halophytes. New Phytologist 179(4):945-963. doi: 10.1111/j.1469-8137.2008.02531.x

Gaines TP, Parker MB, Gascho GJ (1984) Automated determination of chlorides in soil and plant tissue by sodium nitrate. Agronomy Journal 76(3):371-374.

Gengmao Z, Yu H, Xing S, Shihui L, Quanmei S, Changhai W (2015) Salinity stress increases secondary metabolites and enzyme activity in safflower. Industrial Crops and Products 64(1):175-181. doi: 10.1016/j.indcrop.2014.10.058

Guerrero-Rodríguez JD, RevelL DK, Bellotti, WD (2011) Mineral composition of lucerne (Medicago sativa) and white melilot (Melilotus albus) is affected by $\mathrm{NaCl}$ salinity of the irrigation water. Animal Feed Science and Technology 170(1-2):97-104. doi: 10.1016/j.anifeedsci.2011.07.011

Hamed KB, Chibani F, Abdelly C, Magne C (2014) Growth, sodium uptake and antioxidant responses of coastal plants differing in their ecological status under increasing salinity. Biologia 69(2):193-201. doi: 10.1093/aobpla/plv004

Hassan M, Christopher BST, Ghizan S, Ahmad BS, Mohammed EA, Behnam K (2010) Non-destructive estimation of maize leaf area, fresh weight, and dry weight using length and leaf width. Communications in Biometry and Crop Science 5(1):19-26.

Heidari M (2012) Effects of salinity stress on growth, chlorophyll content and osmotic components of two basil (Ocimum basilicum L.) genotypes. African Journal of Biotechnology 11(2):379-384. doi: 10.5897/AJB11.2572

Kafi M, Nabati J, Masoumi A, Mehrgerdi, M Z (2011) Effect of salinity and silicon application on oxidative damage of sorghum [Sorghum bicolor (L.) Moench.]. Pakistan Journal of Botany 43(5):2457-2462.

Kasrati A, Jamali CA, Bekkouche K, Wohlmuth $H$, Leach D, Abbad A (2014) Plant growth, mineral nutrition and volatile oil composition of Mentha suaveolens subsp. timija (Briq.) Harley cultivated under salt stress conditions. Industrial Crops and Products 59:80-84.doi: 10.1016/j.indcrop.2014.05.004 
Lacerda CF, Cambraia J, Oliva Cano MA, Ruiz HA, Prisco JT (2003) Solute accumulation and distribution during shoot and leaf development in two sorghum genotypes under salt stress. Environmental and Experimental Botany 49(2):107-120.

Lacerda CF, Costa RNT, Bezerra MA, Gheyi HR (2010) Estratégias de manejo para uso de água salina na agricultura. In: Gheyi HR, Dias NS, Lacerda CF (eds) Manejo da salinidade na agricultura: Estudos básicos e aplicados. 2ªed, INCT-Sal. p.304-17.

Lacerda CF, Sousa GG, Silva FLB, Guimarães FVA, Silva GL, Cavalcante LF (2011) Soil salinization and maize and cowpea yield in the crop rotation system using saline waters. Engenharia Agrícola 31(4):663675. doi: 10.1590/S0100-69162011000400005

Lima GFC, Silva, JGM, Aguiar EM, Teles MM (2010) Reservas forrageiras estratégicas para a pecuária familiar no semiárido: palma, fenos e silagem. EMPARN,53p.

Lokhande VH, Nikam TD, Patade VY, Ahire ML, Suprasanna P (2011) Effects of optimal and supraoptimal salinity stress on antioxidative defence, osmolytes and in vitro growth responses in Sesuvium portulacastrum L. Plant Cell Tissue and Organ Culture 104(1):41-49. doi:10.1007/s11240-010-9802-9

Majid M, Ali A, Essia B (2012) Effect of salinity on sodium and chloride uptake, proline and soluble carbohydrate contents in three alfalfa varieties. IOSR Journal of Agriculture and Veterinary Science 1(6):01-06 .

Malavolta E, Vitti GC, Oliveira AS (1989) Avaliação do estado nutricional das plantas: Princípios e Aplicações. Associação Brasileira para Pesquisa da Potassa e do Fosfato, 201p.

Mantovani A (1999) A method to improve leaf succulence quantification. Brazilian Archives of Biology and Technology 42(1):9-14. doi: 10.1590/S151689131999000100002.

Marschner H (1995) Mineral nutrition in higher plants. Academic Press, 889p.

Maathuis FJM (2014) Sodium in plants: perception, signalling, and regulation of sodium fluxes. Journal of Experimental Botany 65(3):849-858. doi: 10.1093/jxb/ert326

Matos FS, Rocha EC, Cruvinel CKL, Ribeiro RA, Ribeiro RP, Ticono CF (2013) Desenvolvimento de mudas de pinhão-manso irrigadas com água salina. Revista Brasileira de Ciência do Solo 37(4):947-954. doi: 10.1590/S0100-06832013000400012
Medeiros JF, Nascimento IB, Gheyi HR (2010) Manejo do solo-água-planta em áreas afetadas por sais. In: Gheyi HR, Dias NS, Lacerda CF (eds) Manejo da salinidade na agricultura: Estudos básicos e aplicados. $2^{a}$ ed, INCT-Sal. p.279-302.

Mesquita FO, Cavalcante LF, Rebequi AM, Lima Neto AJ, Nunes JC, Nascimento JAM (2010) Produção de mudas de maracujazeiro amarelo em substrato com biofertilizante bovino irrigado com águas salinas. Agropecuária Técnica 31(2):1-9.

Miransari M (2013) Soil microbes and the availability of soil nutrients. Acta Physiologiae Plantarum 35(11) :3075-3084. doi: 10.1007/s11738-013-1338-2

Mishra DJ, Singh R, Mishra UK, Kumar SS (2013) Role of Bio-Fertilizer in Organic Agriculture: A Review. Research Journal of Recent Sciences 2(2):39-41.

Miyazawa M, Pavan MA, Bloch MFM (1984) Avaliação de métodos com e sem digestão para extração de elementos em tecidos de plantas. Ciência e Cultura 36:1953-1958.

Mohammadi KH, Sohrabi Y (2012) Bacterial biofertilizers for sustainable crop production: a review. Journal of Agricultural and Biological Science 7(5):307316.

Montenegro SGL, Silva Junior JG, Montenegro AAA, Carvalho JF, Albuquerque Filho JAC (2013) Experimentação e modelagem do avanço de sais no perfil do solo em área cultivada com repolho sob alternativas de manejo de irrigação, no semiárido de Pernambuco. Revista Brasileira de Ciências Agrárias 8(1):148-155. doi: 10.5039/agraria.v8i1a1391

Moreira FRDC, Costa NA, Martins TDD, Silva JHVD, Medeiros HRD, Cruz GRBD (2014) Substituição parcial do milho por sorgo granífero na alimentação de suínos nas fases de creche, crescimento e terminação. Revista Brasileira de Saúde e Produção Animal 15(1):94-107. doi: 10.1590/S151999402014000100013

Morgan SH, Maity PJ, Geilfus CM, Lindberg S, Mühling $\mathrm{KH}$ (2014) Leaf ion homeostasis and plasma membrane $\mathrm{H} \mathrm{p}$-ATPase activity in Vicia faba change after extra calcium and potassium supply under salinity. Plant Physiology and Biochemistry 82(82):244253. doi: 10.1016/j.plaphy.2014.06.010

Munns R (2002) Comparative physiology of salt and water stress. Plant, Cell and Environment 25(02): 239250. doi: 10.1046/j.0016-8025.2001.00808.x

Munns R, Tester M. (2008) Mechanisms of salinity tolerance. Annual Review Plant Biology 59:651-681. doi: 10.1146/annurev.arplant.59.032607.092911 
Ngara R, Ndimba R, Borch-Jensen J, Jensen ON, Ndimba B (2012) Identification and profiling of salinity stress-responsive proteins in Sorghum bicolor seedlings. Journal of Proteomics 75(13):4139-4150. doi: 10.1016/j.jprot.2012.05.038.

Nascimento JAM, Cavalcante LF, Dantas SAG, Silva SA (2011) Estado nutricional de maracujazeiroamarelo irrigado com água salina e adubação organomineral. Revista Brasileira de Fruticultura 33(1), 729-735. doi: 10.1590/S0100-29452011000500102.

Nascimento IB, Medeiros JF, Alves SSV, Lima BLC, Silva JLAA (2015) Desenvolvimento inicial do pimentão influenciado pela salinidade da água de irrigação em dois tipos de solos. ACSA - Agropecuária Científica no Semi-Árido 11(1):37-43. doi: 10.1590/1807-1929/agriambi.v19n3p204-210

Neetu V, Swarnkar VK, Das GK (2014) Effect of organic and inorganic sources of nitrogen with biofertilizer on forage sorghum [Sorghum bicolor (L.) Moench]. Trend in Biosciences 7(2):101-103.

Nemati I, Moradi F, Gholizadeh S, Esmaeili MA, Bihamta MR (2011) The effect of salinity stress on ions and soluble sugars distribution in leaves, leaf sheaths and roots of rice (Oryza sativa L.) seedlings. Plant, Soil and Environment 57(1):26-33. doi: 10.17221/71/2010PSE

Niu GH, Osuna P, Sun YP, Rodriguez DS (2012) Seedling emergence, growth, and mineral nutrition of ornamental chili peppers irrigated with saline water. HortScience 47(11):1653-1657.

Oliveira FA, Guedes RAA, Gomes LP, Bezerra FMS, Lima LA, Oliveira MKT (2015) Interação entre salinidade e bioestimulante no crescimento inicial de pinhão-manso. Revista Brasileira de Engenharia Agrícola e Ambiental 19(3):204-210. doi: 10.1590/1807-1929/agriambi.v19n3p204-210

Parida AK, Das AB (2005) Salt tolerance and salinity effects on plants: a review. Ecotoxicology and Environmental Safety 60(3):324-349. doi: 10.1016/j.ecoenv.2004.06.010

Praxedes SC, Lacerda CF, Ferreira TM, Prisco JT, Matta FM, Gomes Filho E (2011) Salt tolerance is unrelated to carbohydrate metabolism in cowpea cultivars. Acta Physiologiae Plantarum 33(3):887-896. doi:10.1007/s11738-010-0615-6

Rady MM, Sadak MSH, El-Bassiouny HMS, El-Monem AA (2011) Alleviation the Adverse effects of salinity stress in sunflower cultivars using nicotinamide and atocopherol. Australian Journal of Basic and Applied Sciences 5(10):342-355.
Rhoades JD, Kandiah A, Mashali AM (1992) The use saline waters for crop production - Irrigation and Drainage Paper 48. FAO.133p.

Saadat S, Homaee, M. (2015) Modeling sorghum response to irrigation water salinity at early growth stage. Agricultural Water Management 152(C):119124. doi: $10.1016 /$ j.agwat.2015.01.008

Sadeghi H, Shourijeh FA (2012) Salinity induced effects on growth parameters, chemical and biochemical characteristics of two forage sorghum (Sorghum bicolor L.) cultivars. Asian Journal of Plant Science 11(1):19-27. doi: 10.3923/ajps.2012.19.27

Saberi AR, Siti Aishah H (2013) Nutrient concentration of forage sorghum (Sorghum bicolor L.) varieties under influenced of salinity and irrigation frequency. The International Journal of Biotechnology 2(10):163-170.

Sahoo RK, Ansari MW, Pradhan M, Dangar TK, Mohanty S, Tuteja N (2014) A novel Azotobacter vinellandii (SRI $\mathrm{Az}$ 3) functions in salinity stress tolerance in rice. Plant Signaling \& Behavior 9(7):511523. doi: $10.4161 /$ psb.29377

Santos FG, Rodrigues JAS, Schaffert RE, Lima JMP, Pitta GVE, Casela CR, Ferreira AS (2007) BRS Ponta Negra - Variedade de Sorgo Forrageiro. EMBRAPA. $6 \mathrm{p}$.

Silva FAS, Azevedo CAV (2016). The Assistat Software Version 7.7 and its use in the analysis of experimental data. African Journal Agricultural Research 11(39):3733-3740. doi: 10.5897/AJAR2016.11522

Silva FLB, Lacerda CF, Sousa GG, Neves ALR, Silva GL, Sousa CHC (2011) Interação entre salinidade e biofertilizante bovino na cultura do feijão-de-corda. Revista Brasileira de Engenharia Agrícola e Ambiental 15(4):383-389.

Silva JLA, Medeiros JF, Alves, SSV, Oliveira FA, Silva Junior MJ, Nascimento IB (2014) Uso de águas salinas como alternativa na irrigação e produção de forragem no semiárido nordestino. Revista Brasileira de Engenharia Agrícola e Ambiental 18(Suplemento):S66S72.

Sousa CHC, Lacerda CF, Bezerra FML, Gomes Filho E, Gheyi HR, Sousa AEC, Sousa GG (2010) Respostas morfofisiológicas de plantas de sorgo, feijão-de-corda e algodão sob estresse salino. Agropecuária Técnica 31(2):29-36. doi: 10.25066/agrotec.v31i2.3971

Sousa AEC, Gheyi HR, Correia KG, Soares FAL, Nobre RG (2011) Crescimento e consumo hídrico de pinhão manso sob estresse salino e doses de fósforo. Revista Ciência Agronômica 42:310-318. 
Sousa GG, Azevedo BM, Albuquerque AHP, Mesquita JBR, Viana TVA (2012a) Características agronômicas do amendoinzeiro sob irrigação com águas salinas em solo com biofertilizantes. Revista Agro@mbiente Online 6(2):124-132. doi: 10.18227/19828470ragro.v6i2.708

Sousa GG, Marinho AB, Albuquerque AHP, Viana, TVA, Azevedo BM (2012b) Crescimento inicial do milho sob diferentes concentrações de biofertilizante bovino irrigado com águas salinas. Revista Ciência Agronômica 43(2):237-245.

Sucre B, Suarez N (2011) Effect of salinity and PEGinduced water stress on water status, gas exchange, solute accumulation, and leaf growth in Ipomoea pescaprae. Environmental and Experimental Botany 70:192-203. doi: 10.1016/j.envexpbot.2010.09.004

Sun $Y$, Niu G, Osuna P, Zhao L, Ganjegunte G, Peterson G, Peralta-Videa JR, Gardea-Torresdey JL (2014) Variability in salt tolerance of Sorghum bicolor L. Agricultural Science 2(1):09-21. doi: 10.12735/as.v2i1p9

Talaat NB, Shawky BT (2014) Protective effects of arbuscular mycorrhizal fungi on wheat (Triticum aestivum L.) plants exposed to salinity. Environmental and Experimental Botany 98:20-31. doi: 10.1016/j.envexpbot.2013.10.005

Taiz L, Zeiger E (2009) Fisiologia vegetal. 4. ed. ArtMed, 848p

Tang J, Camberato JJ, Yu X, Luo N, Bian S, Jiang Y (2013) Growth response, carbohydrate and ion accumulation of diverse perennial ryegrass accessions to increasing salinity. Scientia Horticulturae 154:73-81. doi: 10.1016/j.scienta.2013.02.021
Tawfik MM, Abd El Lateef, EM, Amany, AB, Hozayen $M$ (2011) Prospect of Biofertilizer Inoculation for Increasing Saline Irrigation Efficiency. Research Journal of Agriculture and Biological Sciences 7(2):182-189.

Trindade AR, Lacerda CF, Gomes Filho E, Bezerra MA, Prisco JT (2006) Influência do acúmulo e distribuição de íons sobre a aclimatação de plantas de sorgo e feijão-de-corda, ao estresse salino. Revista Brasileira de Engenharia Agrícola e Ambiental 10:804810. doi: 10.1590/S 1415-43662006000400004

Van Horn DJ, Okie JG, Buelow HN, Gooseff MN, Barrett JE, Takacs-Vesbach CD (2014) Soil microbial responses to increased moisture and organic resources along a salinity gradient in a polar desert. Applied and Environmental Microbiology 80(10):30343043. doi: 10.1128/AEM.03414-13

Vianello RL, Alves AR (1991) Meteorologia Básica e Aplicações. UFV Imprensa Universitária. 449p.

Wong $\mathrm{JH}$, Marxb DB, Wilsonc JD, Buchanana BB, Lemauxa PG, Pedersend JF (2010) Principal component analysis and biochemical characterization of protein and starch reveal primary targets for improving sorghum grain. Plant Science 179(6):598611. doi: 10.1016/j.plantsci.2010.08.020

Zhang ZH, Qiang L, Song HX, Rong XM, Ismail AM (2012) Responses of different rice (Oryza sativa L.) genotypes to salt stress and relation to carbohydrate metabolism and chlorophyll content. African Journal of Agricultural Research 7(1):19-27. doi: 10.5897/AJAR11.834

Zhao X, Shi Y, Liu Y, Jia RL, Li XR (2015) Osmotic adjustment of soil biocrust mosses in response to desiccation stress. Pedosphere 25(3):459-467. doi: 10.1016/S1002-0160(15)30013-8 